\title{
Comparative Transcriptome Analysis of Spleen Reveals Potential Regulation of Genes and Immune Pathways Following Administration of Aeromonas salmonicida subsp. masoucida Vaccine in Atlantic Salmon (Salmo salar)
}

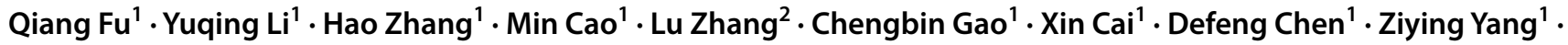 \\ Jie $\mathrm{Li}^{3} \cdot$ Ning Yang ${ }^{1} \cdot \mathrm{Chao} \mathrm{Li}^{1}{ }^{1}$
}

Received: 13 August 2021 / Accepted: 17 December 2021 / Published online: 27 January 2022

(c) The Author(s), under exclusive licence to Springer Science+Business Media, LLC, part of Springer Nature 2022

\begin{abstract}
Aeromonas salmonicida is a global fish pathogen. Aeromonas salmonicida subsp. masoucida (ASM) is classified as atypical A. salmonicida and caused huge losses to salmonid industry in China. Hence, it is of great significance to develop ASM vaccine and explore its protection mechanism in salmonids. In this regard, we conducted RNA-seq analysis with spleen tissue of Atlantic salmon after ASM vaccination to reveal genes, their expression patterns, and pathways involved in immune protections. In our results, a total of 441.63 million clean reads were obtained, and 389.37 million reads were mapped onto the Atlantic salmon reference genome. In addition, 1125, 2126, 1098, 820, and 1351 genes were significantly up-regulated, and 747, 2626, 818, 254, and 908 genes were significantly down-regulated post-ASM vaccination at $12 \mathrm{~h}, 24 \mathrm{~h}, 1$ month, 2 months, and 3 months, respectively. Subsequent pathway analysis revealed that many differentially expressed genes (DEGs) following ASM vaccination were involved in cytokine-cytokine receptor interaction (TNFRSF11b,IL-17RA, CCR9, and $C X C L 11$ ), HTLV-I infection (MR1 and $H T L V-1$ ), MAPK signaling pathway (MAPK, IL8, and TNF- $\alpha-1$ ), PI3K-Akt signaling pathway (PIK3R3, THBS4, and COL2A1), and TNF signaling pathway (PTGS2, TNFRSF21-l, and CXCL10). Finally, the results of qRT-PCR showed a significant correlation with RNA-seq results, suggesting the reliability of RNA-seq for gene expression analysis. This study provided insights into regulation of gene expression and their involved pathways in Atlantic salmon spleen in responses to vaccine, and set the foundation for further study on the vaccine protective mechanism in Atlantic salmon as well as other teleost species.
\end{abstract}

Keywords Aeromonas salmonicida $\cdot$ Atlantic salmon $\cdot$ Vaccination $\cdot$ Spleen $\cdot$ RNA-seq

\section{Introduction}

Atlantic salmon (Salmo salar), one of the most economically important fish utilized for aquaculture, is a key species in marine and freshwater ecosystems and has a high economic value to

Qiang Fu and Yuqing Li contributed equally to this work.

Chao Li

chaoli@qau.edu.cn

1 School of Marine Science and Engineering, Qingdao Agricultural University, Qingdao 266109, China

2 Shandong Sinder Technology Co., Ltd, Zhucheng 262200, China

3 Key Laboratory of Maricultural Organism Disease Control, Yellow Sea Fisheries Research Institute, Chinese Academy of Fishery Sciences, Qingdao, China ecotourism and fisheries (Andrew et al. 2021; Wang et al. 2019). The economic importance of this species as well as other factors have led to it becoming a model species for biological research (Andrew et al. 2021). Atlantic salmon is by quantity the largest species of salmonids produced worldwide (FAO, 2018), and they are mainly farmed in cold waters in Northern Europe, North America, Chile, and Tasmania (Gjessing et al. 2020), and were introduced into China using recirculating aquaculture system (RAS) in 2010 due to their high nutritional and economic value (Wang et al. 2019). The anadromous salmon life cycle is mimicked in aquaculture, where juvenile fish are farmed in indoor fresh water facilities, artificially smoltified, and then transferred to sea water for the grow-out phase (Gjessing et al. 2020).

Aeromonas salmonicida is an important bacterial fish pathogen causing furunculosis in many different freshwater and marine fish species worldwide (Dallaire-Dufresne et al. 
2014) and causes significant economic losses to global Atlantic salmon industry (Janda and Abbott 2010). A. salmonicida is a non-motile psychrophilic species made up of five subspecies (salmonicida, achromogenes, masoucida, pectinolytica, and smithia) (Garrity 2001). A. salmonicida subsp. salmonicida (ASS) was classified as "typical" and any isolate deviating phenotypically was regarded as "atypical" (Reith et al. 2008). In a recent study, $A$. salmonicida subspecies were divided into either of 14 distinct clusters or A-layer types based on partial nucleotide sequences of the virulence array protein (vapA) gene (Gulla et al. 2016). A. salmonicida subsp. masoucida (ASM) strains, isolated from China, Japan, and South Korea, were clustered in cluster VII among these 14 clusters. Several ASM strains were recently isolated from aquaculture farm of salmon in the city of Yantai, China, and were reported to bring huge economic damages to the local salmonid aquaculture (Du et al. 2015; Yan et al. 2021). Although the host response to the bacterium and vaccination has been well documented for A. salmonicida (Gudmundsdottir et al. 2010; Midtlyng et al. 1996a; Villumsen et al. 2012; Du et al. 2015), the effective ASM vaccine is still lacking, and little is known on the molecular mechanisms of host immune response after ASM vaccination.

Fish maintains a healthy state by defending itself against environmental pathogens by a complex system of innate defense mechanisms (Magnadóttir 2006). The spleen is regarded as the primordial secondary lymphoid organ, and almost all gnathostomes possess this organ in which adaptive immune responses are generated, concentrating the antigens for interactions between antigen-specific T cells, B cells and antigen-presenting cells (APCs) (Flajnik 2018; Bjørgen and Koppang 2021; Qi et al. 2016). Teleost spleen is the major source of immunoglobulin and play vital roles in preventing further lesions during bacterial infections ( $\mathrm{Li}$ et al. 2015). In addition, the teleost spleen was reported to be capable of initiating the immune responses associated with calcium (Hwang et al. 2015), and producing immune globulin (Grove et al. 2006) and various lytic enzymes (Milla et al. 2010) to protect fish against pathogens.

Transcriptome, as an effective analysis tool, enables an in-depth study of complicated physiological pathways, including development, immune responses, physiology, cellular fate, and disease progression (Maekawa et al. 2019; Wang et al. 2009). Recently, transcriptomics technologies have been fully utilized to explore the participations of teleost spleen in response to different pathogens (Ali et al. 2014; Papetti et al. 2015; Kim et al. 2020). However, the information on the roles of Atlantic salmon spleen during immune activities at the transcriptional level is quite limited, even if the transcriptional responses were explored in Atlantic salmon in several tissues including blood, liver, head kidney, and gill (Andrew et al. 2020; Martin et al. 2006; Botwright et al. 2021). To expand the knowledge at the molecular level, we conducted RNA-seq analysis to identify the differentially expressed genes (DEGs) and the immune signaling pathway they involved in Atlantic salmon spleen after intraperitoneal injection of ASM vaccine. These findings will contribute to fish immunotherapy for the prevention and treatment of bacterial infections through the design of more specific and effective immune stimulants, adjuvants, and vaccines. Our results can also set the foundation for further developing of biomarkers, characterizing the mechanisms of immune organ barriers for vaccine development, and expanding our knowledge of teleost immunology.

\section{Material and Methods}

\section{Ethics Statement}

All experiments were performed according to local government regulations, and the procedures and protocols involving handling and treatment of fish were approved by the Institutional Animal Care and Use Committee of Qingdao Agricultural University.

\section{Preparation of $A$. salmonicida subsp. masoucida Vaccines}

Aeromonas salmonicida subsp. masoucida (strain RZ6S-1) was isolated from diseased cultured Atlantic salmon in a farm located in Yantai, Shandong province. The strain was stored in $15 \%$ glycerol (Sangon, China) at $-80{ }^{\circ} \mathrm{C}$ in laboratory until passage on tryptone soy agar supplemented with $1.5 \% \mathrm{NaCl}(\mathrm{w} / \mathrm{v})$ (TSA) for $50 \mathrm{~h}$, immediately before use. Bacteria were cultured in tryptone soy broth supplemented with $1.5 \% \mathrm{NaCl}(\mathrm{TSB})$ for approximately $12 \mathrm{~h}$ at $20{ }^{\circ} \mathrm{C}$ prior to use during the production of vaccine.

Aeromonas salmonicida subsp. masoucida (strain RZ6S1) were cultured in TSB medium and centrifuged at $4000 \mathrm{~g}$ for $10 \mathrm{~min}$. Bacteria were resuspended in $0.2 \mathrm{M}$ phosphate buffer saline (PBS, $0.145 \mathrm{M} \mathrm{Na}_{2} \mathrm{HPO}_{4} \cdot 12 \mathrm{H}_{2} \mathrm{O}, 0.055 \mathrm{M}$ $\mathrm{NaH}_{2} \mathrm{PO}_{4} \cdot 2 \mathrm{H}_{2} \mathrm{O}, \mathrm{pH} 7.4$ ), and inactivated with $0.2 \%$ formalin at $20{ }^{\circ} \mathrm{C}$ for $24 \mathrm{~h}$, and $4{ }^{\circ} \mathrm{C}$ for $72 \mathrm{~h}$. Success of inactivation of bacteria was checked by culturing on TSA for 7 days. Inactivated RZ6S-1 was suspended with PBS to approximately $2 \times 10^{9} \mathrm{CFU} / \mathrm{mL}$ and emulsified with the oil adjuvant Marcol 52 (MOBIL ${ }^{\mathrm{TM}}$, USA) at a ratio of 4:6 to form an oil-based vaccine (Yan et al. 2021).

\section{Experimental Fish and Vaccine Injection}

Atlantic salmon were obtained from a farm located in Yantai, Shandong province. Fish were cultured in ponds ( $7 \mathrm{~m} \times 7 \mathrm{~m} \times 0.5 \mathrm{~m})$ equipped with recirculating aquaculture system (RAS) $14 \pm 2{ }^{\circ} \mathrm{C}$, with continuous underground 
seawater (infiltrated coastal seawater, flow-through $6000-9000 \mathrm{~L} / \mathrm{h}$ ). The seawater salinity, the $\mathrm{pH}$, and the dissolved oxygen was $2.7 \pm 0.2 \%, 7.6 \pm 0.1$, and $7.0 \pm 0.5 \mathrm{mg} / \mathrm{L}$, respectively. Fish were fed twice (in case of disease outbreak only once) a day with commercial feed (Shengsuo, China), and the daily feeding rate was set at $1.2 \pm 0.1 \%$ of fish weight at $0-8$ weeks, $1 \pm 0.1 \%$ at $9-16$ weeks, and $0.9 \pm 0.1 \%$ at 16-24 weeks. Before the vaccination, 20 fish were randomly selected, euthanized with an overdose of MS-222 (200 mg/L, Yibaolai, China), and examined microscopically for the presence of parasites. Samples were taken from internal organs for bacterial analysis on TSA plates to confirm that the fish were not infected by A. salmonicida.

A total of 5000 fish $(33.56 \pm 1.45 \mathrm{~g})$ were randomly selected and equally divided into two ponds (2500 fish each), and then cultured with continuous underground seawater at $14 \pm 2{ }^{\circ} \mathrm{C}$. One pond was designated as experimental group, and fish were intraperitoneally vaccinated using a repeater syringe with $0.1 \mathrm{~mL}$ Marcol 52 emulsified vaccines, containing $10^{8}$ cells/fish of $A$. salmonicida subsp. masoucida. Fish of the control group were cultured in another pond under the same conditions without vaccination. All the fish were cultured as normal production by the experienced workers. The experiment was conducted over 3 months, and 30 fish (10 fish $\times 3$ replicates) were randomly selected and euthanized with MS-222 (200 mg/L, Yibaolai, China) from each pond at $12 \mathrm{~h}$ (AS_12h), $24 \mathrm{~h}$ (AS_24h), 1 month (AS_1m), 2 months (AS_2m), and 3 months (AS_3 m) post-vaccination. The spleens from 10 fish were dissected and pooled together as one biological replicate, and a total of three replicate pooled samples were collected for each time point. All samples were flash-frozen in liquid nitrogen and then stored in an ultra-low freezer at $-80{ }^{\circ} \mathrm{C}$ until RNA extraction.

\section{RNA Extraction, Library Construction, and Sequencing}

Total RNA was extracted from the tissue samples using Trizol ${ }^{\circledR}$ Reagent (Invitrogen, USA), and 1\% agarose gels were used to monitor the integrity of the RNA. After extraction, contaminating DNA was digested with RNase-Free DNase I (TIANGEN, Beijing, China) under the guidance of the instructions. Then, all RNA samples were run on the gel to ensure that no genomic DNA existed. The RNA quality and quantity of each sample were determined by Nanodrop 2000 (Thermo electronic North America LLC, FL). All extracted samples with A260/280 and A260/230 greater than 1.8 and RNA integrity number (RIN) greater than 7.0 were used for cDNA library construction. NanoPhotometer spectrophotometer (IMPLEN, CA, USA) was used to check RNA concentration. Three replicate samples were processed for each time point, and a total of 18 libraries were generated and sequenced.
NEBNext Ultra ${ }^{\mathrm{TM}}$ RNA Library Prep Kit for Illumina (NEB, USA) were used to generate sequencing libraries following manufacturer's recommendations, and index codes were added to attribute sequences to each sample. Briefly, poly-T oligo-attached magnetic beads were used to purify mRNA from total RNA. Divalent cations were used to carry out fragmentation under elevated temperature in NEBNext ${ }^{\circledR}$ First Strand Synthesis Reaction Buffer (5X). First strand cDNA was synthesized using random hexamer primer and M-MuLV Reverse Transcriptase $\left(\mathrm{RNaseH}^{-}\right)$. Subsequently, DNA polymerase I and RNase $\mathrm{H}$ were used to perform second strand cDNA synthesis. Remaining overhangs were converted into blunt ends via exonuclease/polymerase activities. After adenylation of $3^{\prime}$ ends of DNA fragments, NEBNext ${ }^{\circledR}$ Adaptors with hairpin loop structure were ligated to prepare for hybridization. The library fragments were purified with AMPure XP system (Beckman Coulter, Inc., Beverly, USA) to select cDNA fragments of preferentially $150-200 \mathrm{bp}$ in length. Then, $3 \mu \mathrm{l}$ USER Enzyme (NEB, USA) was used with size-selected, adaptorligated cDNA at $37^{\circ} \mathrm{C}$ for $15 \mathrm{~min}$ followed by $5 \mathrm{~min}$ at $95^{\circ} \mathrm{C}$ before PCR. Then, PCR was performed with Phusion® HighFidelity DNA Polymerase, Universal PCR primers and Index (X) Primer. At last, PCR products were purified (AMPure XP system) and library quality was assessed on the Agilent 2100 Bioanalyzer system. The clustering of the index-coded samples was performed on a cBot Cluster Generation System using TruSeq SR Cluster Kit v3-cBot-HS (Illumina) according to the manufacturer's instructions. After cluster generation, eighteen spleen sequencing libraries (three replicates of $0 \mathrm{~h}, 12 \mathrm{~h}, 24 \mathrm{~h}$, 1 month, 2 months, and 3 months, respectively) were sequenced on an Illumina Hiseq 2500 platform, and 150 bp paired-end reads were generated.

\section{Reads Mapping and Differential Expression Analysis}

FastQC (http://www.bioinformatics.babraham.ac. uk/projects/fastqc/) was used to assess the quality of sequencing data before and after trimming to make sure high-quality sequences were used in subsequent analysis. Trimmomatic (version 0.32) (Bolger et al. 2014) was used to trim raw reads by removing adapter sequences and ambiguous nucleotides. Only reads where both pairs had a length greater than $30 \mathrm{bp}$ post-filtering were retained. Hisat 2 was used to map the filtered reads to the Atlantic salmon genome reference (Lien et al. 2016), 5\% mismatch of the mapped length was allowed and the minimum $90 \%$ of the bases matched to the genome was restricted. The HTSeq-count was used to extract read counts from the mapping profiles with the recommended mode (Anders et al. 2015).

EdgeR (Robinson et al. 2010) was used to conduct the trimmed mean of M-values normalization of expression value for each group in order to illustrate differentially 
expressed pattern. Differential expression between treatment and control samples was calculated with DEGseq (version 1.18.0) (Likun et al. 2010), and resulting $P$ values were corrected for false discovery rate (FDR). DEGs were defined as showing FDR corrected $P$ value $<0.05$ and absolute value of $\log _{2}$ (fold change) $>1$. Venn diagram and volcano plot was used to intuitively display the DEGs of different time points.

\section{Gene Ontology and Enrichment Analysis}

DEGs were annotated by gene ontology (GO) functional enrichment with the GO-TermFinder (V 0.86), and $P$ values $<0.05$ were considered significant difference (Boyle et al. 2004). The DEGs were enriched into three GO categories including biological process, molecular function, and cellular component at level 2. Pathway analysis was performed with the Kyoto Encyclopedia of Genes and Genomes (KEGG) database (http://www.genome.jp/kegg) (Kanehisa 2013), combined with manual literature review. Pathways with $q$-value $<0.05$ were significantly enriched in DEGs after multiple test correction.

\section{Experimental Validation by Quantitative Real-Time PCR}

To confirm the reliability of RNA-seq results, we randomly selected 18 immune-related DEGs for qRT-PCR validation. The specific primers of all these genes were designed by PrimerQuest (https://sg.idtdna.com/PrimerQuest/Home) and listed in Table 1 . The specificity of primers was assessed by aligning with the Atlantic salmon whole genome database (Lien et al. 2016) using BLASTN with E-value of $1 \mathrm{e}^{-10}$. Reverse transcription was performed with $1 \mu \mathrm{g}$ total RNA using the qScript ${ }^{\mathrm{TM}}$ cDNA Synthesis Kit (Quanta Bioscience, Gaithersburg, MD). All the cDNA products were then diluted to $250 \mathrm{ng} / \mu \mathrm{L}$ with DNase/RNase-Free water (Solaribio, Beijing, China). The qPCR was performed using SYBR Green PCR Master Mix on a CFX96 real-time PCR detection system (BioRad, USA). The cycling conditions of qPCR were denaturation, $95^{\circ} \mathrm{C} / 30 \mathrm{~s}, 40$ cycles of $95{ }^{\circ} \mathrm{C} / 5 \mathrm{~s}, 60^{\circ} \mathrm{C} / 5 \mathrm{~s}$, and $72{ }^{\circ} \mathrm{C} / 5 \mathrm{~s}$. Test PCR was performed in advance to ensure all the genes were amplified with expect PCR product sizes. A no-template control was run on all plates. The Atlantic salmon $\beta$-actin gene was used as an internal reference gene (Ingerslev et al. 2006). For the transcriptome libraries preparation, first strand cDNA (500 ng RNA per $10 \mu \mathrm{L}$ reaction) was synthesized by PrimeScript ${ }^{\mathrm{TM}} \mathrm{RT}$ reagent Kit (Takara, Otsu, Japan) according to manufacturer's protocol. The expression levels of those genes were detected by a CFX96 real-time PCR detection system (Bio-Rad Laboratories, Hercules, CA) following the manufacturer's instructions. The reactions were performed in $20 \mu \mathrm{L}$ volumes containing $2 \mu \mathrm{L}$ of the diluted template cDNA, $0.6 \mu \mathrm{L}$ of each primer $(10 \mu \mathrm{M}), 10 \mu \mathrm{L}$ of SYBR ${ }^{\circledR}$ Premix Ex TaqTM II (TliRNaseH Plus), and $6.8 \mu \mathrm{L}$ of RNA-free water.
The thermal cycling profile was performed as follows. The PCR reaction mixture was denatured at $95^{\circ} \mathrm{C}$ for $30 \mathrm{~s}$ and followed by 40 cycles of $95{ }^{\circ} \mathrm{C}$ for $30 \mathrm{~s}, 58^{\circ} \mathrm{C}$ for $30 \mathrm{~s}$ and followed by dissociation curve analysis, $5 \mathrm{~s}$ at $65^{\circ} \mathrm{C}$, then up to $95{ }^{\circ} \mathrm{C}$ at a rate of $0.1^{\circ} \mathrm{C} / \mathrm{s}$ increment, to verify the specificity of the amplicons. No-template controls were performed as negative control for each gene, and each reaction was confirmed by repeating in triplicates for the qPCR analysis. Finally, $2^{-\Delta \Delta \mathrm{Ct}}$ method was used to calculate the relative gene expression fold changes (Livak and Schmittgen 2001). The qPCR was repeated in triplicate runs to confirm expression patterns.

\section{Results}

\section{Sequencing and Mapping of Short Expressed Reads}

RNA-seq analysis was performed to generate the expressed short reads from the spleen of Atlantic salmon in control group $(0 \mathrm{~h})$ and vaccination-treated groups ( $12 \mathrm{~h}, 24 \mathrm{~h}, 1$ month, 2 months, and 3 months), and the results are summarized in Table 2. A total of 441,630,681 clean reads were obtained after removing low-quality reads, rRNA reads, reads containing adapters, and reads with $>10$ unknown nucleotides. The sequence data were deposited at the NCBI Sequence Read Archive (SRA) with Bioproject number PRJNA786357. After filtering, the Q20 and Q30 were $94.86-96.87 \%$ and $88.44-92.57 \%$, respectively, indicating that the sequencing data were of high quality. In addition, the average percentage of sequences successfully mapped onto the Atlantic salmon reference genome was $88.17 \%$, resulted in a total of 389,373,457 mapped reads (Table 2).

\section{Analysis of Differentially Expressed Genes}

In order to identify DEGs in Atlantic salmon spleen, pairwise comparisons were performed between control groups $(0 \mathrm{~h})$ and experimental groups (12 h, $24 \mathrm{~h}, 1$ month, 2 months, and 3 months). The number of DEGs at different time points postASM vaccination are presented in Fig. 1 and Table 3. A total of $1872 \mathrm{DEGs}$ were identified at $12 \mathrm{~h}$ post-vaccination, with 1125 DEGs up-regulated and 747 DEGs down-regulated. Subsequently, there were 4752 DEGs identified at $24 \mathrm{~h}$ postvaccination, with 2126 DEGs up-regulated and 2626 DEGs down-regulated. Moreover, a total of 1916, 1074, and 2259 DEGs were identified at 1,2 , and 3 months post-vaccination, with 1098, 820, and 1351 DEGs up-regulated, and 818, 254, and 908 DEGs down-regulated, respectively (Fig. 1A-E and Table 3). Noteworthily, the number of up-regulated DEGs was higher than down-regulated DEGs at all tested time points, except for the $24 \mathrm{~h}$. For the intersection analysis, a total of 119 DEGs were shared among all different time points postvaccination (Fig. 1F). 


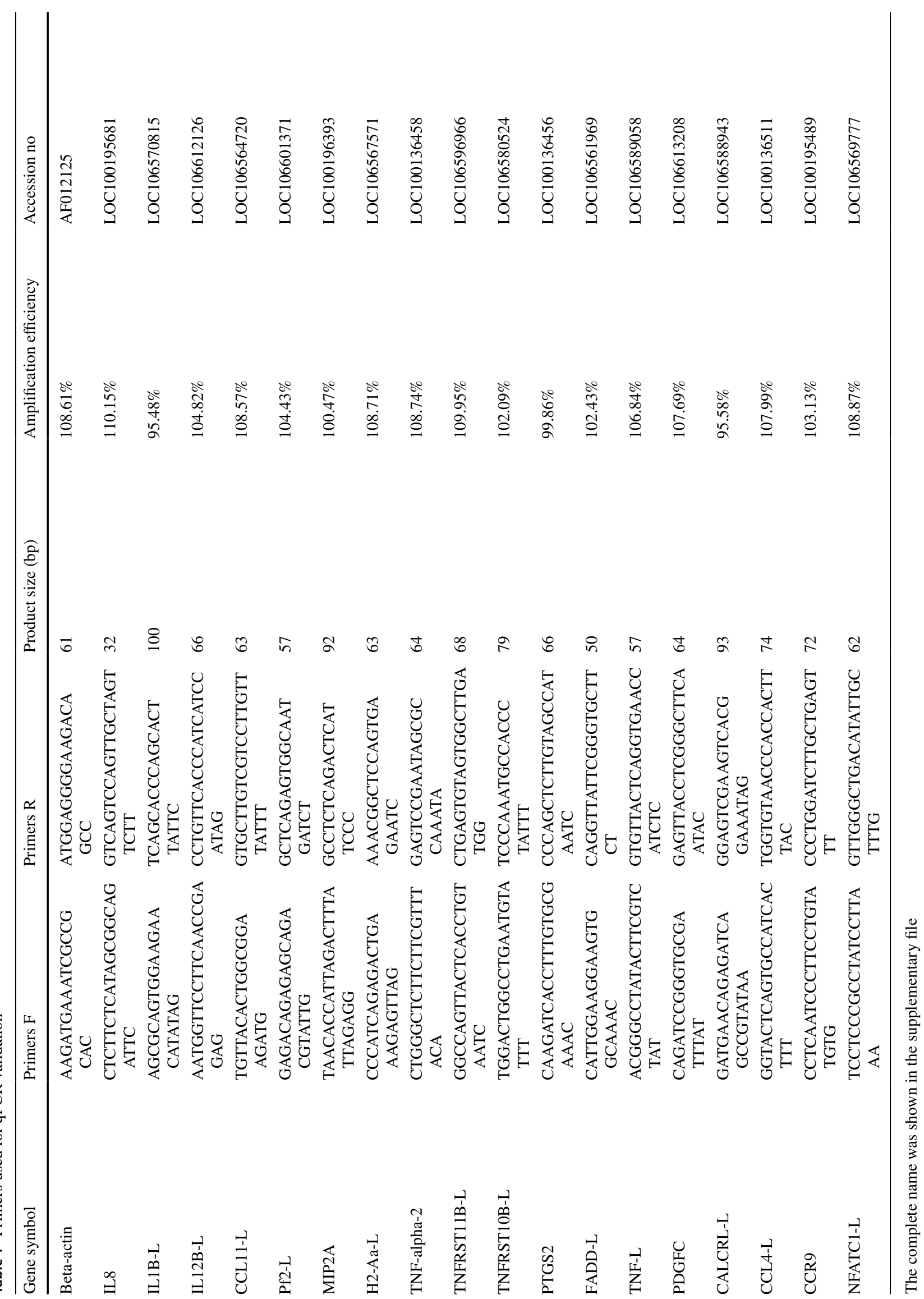


Table 2 Summary of RNA-seq of Atlantic salmon spleen transcriptomes post-ASM vaccination

\begin{tabular}{|c|c|c|c|c|c|c|}
\hline Sample name & Clean reads $(\mathrm{bp})$ & Clean bases (bp) & Clean GC & Clean Q20 & Clean Q30 & Total mapped reads (\%) \\
\hline Spleen-0 h-1 & $23,990,624$ & $6,517,245,648$ & 48.26 & 96.58 & 92.04 & $21,406,834(89.23 \%)$ \\
\hline Spleen-0 h-2 & $21,784,367$ & $7,232,369,024$ & 48.15 & 96.73 & 92.34 & $19,468,689(89.37 \%)$ \\
\hline Spleen- 0 h-3 & $24,176,459$ & $8,241,674,628$ & 48.57 & 96.87 & 92.57 & $21,282,537(88.03 \%)$ \\
\hline Spleen-12 h-1 & $27,647,896$ & $7,577,562,270$ & 48.31 & 95.69 & 89.97 & $24,108,966(87.20 \%)$ \\
\hline Spleen-12 h-2 & $25,369,710$ & $8,589,785,570$ & 48.08 & 94.88 & 88.45 & $21,894,060(86.30 \%)$ \\
\hline Spleen-12 h-3 & $28,744,767$ & $7,158,238,314$ & 47.45 & 94.86 & 88.45 & $25,263,776(87.89 \%)$ \\
\hline Spleen-24 h-1 & $23,979,715$ & $6,212,895,586$ & 48.58 & 94.93 & 88.56 & $20,975,057(87.47 \%)$ \\
\hline Spleen-24 h-2 & $20,939,499$ & $7,208,112,598$ & 46.44 & 95.68 & 89.97 & $18,805,765(89.81 \%)$ \\
\hline Spleen-24 h-3 & $24,232,981$ & $6,028,183,378$ & 47.31 & 95.05 & 88.82 & $21,475,268(88.62 \%)$ \\
\hline Spleen-1 m-1 & $20,190,911$ & $6,392,119,708$ & 47.98 & 96.23 & 91.34 & $17,832,613(88.32 \%)$ \\
\hline Spleen-1 m-2 & $21,396,364$ & $6,386,269,348$ & 46.93 & 94.89 & 88.44 & $18,963,598(88.63 \%)$ \\
\hline Spleen-1 m-3 & $21,428,207$ & $6,943,521,486$ & 47.11 & 95.81 & 90.50 & $18,878,251(88.10 \%)$ \\
\hline Spleen-2 m-1 & $23,197,668$ & $6,802,255,556$ & 48.57 & 96.32 & 91.49 & $20,516,018(88.44 \%)$ \\
\hline Spleen-2 m-2 & $22,837,050$ & $8,049,544,156$ & 46.32 & 95.47 & 89.60 & $20,299,854(88.89 \%)$ \\
\hline Spleen-2 m-3 & $26,922,069$ & $9,479,971,644$ & 48.30 & 96.79 & 92.55 & $23,594,502(87.64 \%)$ \\
\hline Spleen-3 m-1 & $31,850,655$ & $8,593,044,178$ & 47.98 & 96.86 & 92.44 & $28,334,343(88.96 \%)$ \\
\hline Spleen-3 m-2 & $28,887,121$ & $7,133,708,518$ & 47.21 & 95.88 & 90.72 & $25,677,762(88.89 \%)$ \\
\hline Spleen-3 m-3 & $24,054,618$ & $6,517,245,648$ & 48.47 & 95.57 & 89.62 & $20,595,564(85.62 \%)$ \\
\hline Total & $441,630,681$ & $131,063,747,258$ & & & & $389,373,457(88.17 \%)$ \\
\hline
\end{tabular}
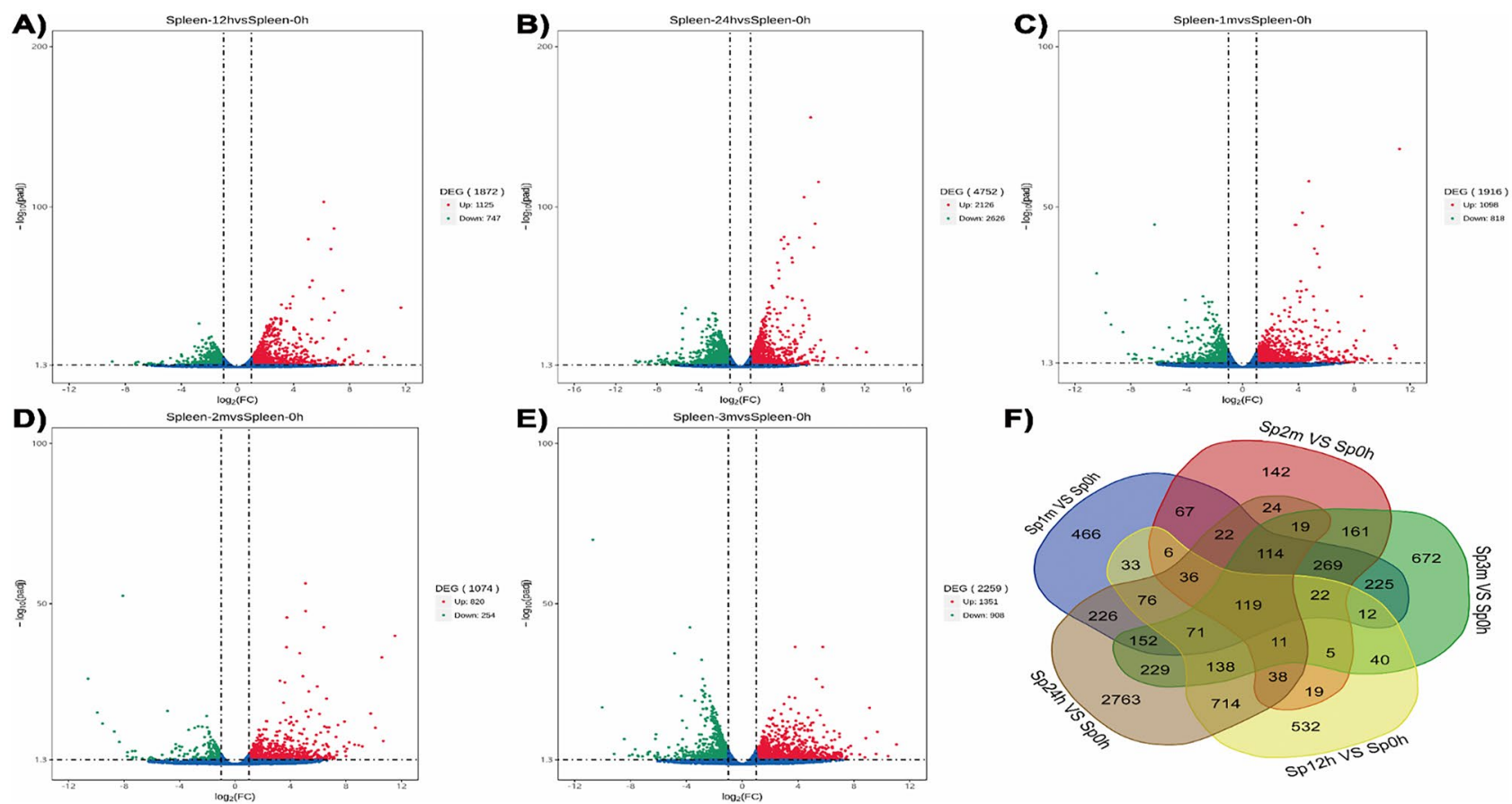

Fig. 1 Analysis of DEGs displayed through volcano plot and Venn diagram in Atlantic salmon spleen at different time points post-vaccination. A-E Volcano plot of DEGs in Atlantic salmon spleen at $12 \mathrm{~h}, 24 \mathrm{~h}, 1$ month, 2 months, and 3 months, respectively. The $x$-axis represents the value of $\log _{2}$ (fold change), and the $y$-axis represents the value of $-\log _{10}$ (FDR). Red and green spots represent significantly up-regulated and down-regulated genes, respectively ( $\log _{2}$ (fold change) $\mid>1$ ) while blue spots represent no difference in gene expression. F Venn diagram 
Table 3 Summary of DEGs in Atlantic salmon spleen at different time points post ASM vaccination with a cutoff of FDR-corrected $P$ value $<0.05$ and $\log _{2}$ (fold change) $\mid>1$

\begin{tabular}{llllll}
\hline DEGs & $12 \mathrm{~h}$ & $24 \mathrm{~h}$ & 1 month & 2 months & 3 months \\
\hline Up-regulated & 1125 & 2126 & 1098 & 820 & 1351 \\
Down-regulated & 747 & 2626 & 818 & 254 & 908 \\
Total & 1872 & 4752 & 1916 & 1074 & 2259 \\
\hline
\end{tabular}

\section{Analysis of Expression Signatures, Clustering, and GO Analysis}

The expression signatures and hierarchical clustering of all DEGs were displayed with heatmap diagram. On the one hand, spleen samples of Atlantic salmon in control and vaccination groups at 2 months were firstly clustered together, and then clustered with vaccination-treated groups at 1 month and 3 months. On the other hand, the spleen samples of Atlantic salmon in $12 \mathrm{~h}$ and $24 \mathrm{~h}$ were clustered together, and finally fell into the other clade mentioned above. In addition, six major clusters of DEGs were observed based on their expression signatures (Fig. 2). For instance, the cluster 1 of DEGs were gradually up-regulated at different time points. Meanwhile, the cluster 6 of DEGs were firstly gradually downregulated at $12 \mathrm{~h}$ and $24 \mathrm{~h}$, and then gradually up-regulated at 1 month, 2 months, and 3 months.

To explore the biological functions of DEGs, GO analysis was performed at level two. Enriched GO terms were classified to biological process (BP), cellular component (CC), and molecular function (MF). On the one hand, the GO analysis results of up-regulated DEGs are presented at Fig. 3A. In BP, single-organism-metabolic-process (GO:0,044,723), immune system process (GO:0,002,376), and response to external stimulus (GO:0,009,605) were the most annotated terms. In MF category, oxidoreductase activity (GO:0,016,491) was the most annotated term. Under CC category, membrane (GO:0,005,886), membrane-part (GO:0,044,425), intrinsic component of membrane (GO:0,031,224), and integral component of membrane (GO:0,016,021) were the most common annotated terms. On the other hand, the GO analysis results of down-regulated DEGs are presented in Fig. 3B. In BP category, biological regulation (GO:0,065,007) and regulation of biological process (GO:0,050,789) were the two most enriched GO terms. Under molecular function category, signal transducer activity (GO:0,004,871), receptor activity (GO:0,004,872), and molecular transducer activity (GO:0,060,089) were the most enriched GO terms. Under cellular component category, extracellular region (GO:0,005,576) and extracellular matrix (GO:0,030,198) were the GO terms represented by the highest numbers of DEGs.

\section{Signaling Pathway Analysis}

KEGG analysis significantly revealed a large number of immune-related pathways. A total of 2305 genes were assigned into KEGG functional pathways in Atlantic salmon spleen after vaccination treatment, and forty representative pathways were selected and presented in Fig. 4. On the one hand, 1050 up-regulated DEGs were assigned to twenty pathways such as cytokine-cytokine receptor interaction (116 DEGs), NOD-like receptor signaling pathway (40 DEGs), tumor necrosis factor (TNF) signaling pathway (61 DEGs), NF-kappa B signaling pathway (52 DEGs), intestinal immune network for $\lg$ A production (32 DEGs), and antigen processing and presentation (37 DEGs). On the other hand, 1255 down-regulated DEGs were enriched into another twenty pathways including pathways in cancer (169 DEGs), cytokine-cytokine receptor interaction (79 DEGs), intestinal immune network for $\lg$ A production (24 DEGs), PI3K-Ak signaling pathway (127 DEGs), and B cell receptor signaling pathway (41 DEGs).

Based on a combination of enrichment analysis, pathway analysis, manual annotation, and literature researches, representative DEGs were arranged into five categories according to functional pathways, including cytokinecytokine receptor interaction, HTLV-I infection, MAPK signaling pathway, PI3K-Akt signaling pathway, and TNF signaling pathway (Table 4). Putative pathways involved in immunity response in Atlantic salmon spleen after vaccination treatment were illustrated in the context of a diagram (Fig. 5).

\section{Validation of RNA-seq Results by qRT-PCR}

To validate the DEGs identified by RNA-seq, we randomly selected eighteen immune-related genes for RTqPCR validation. As shown in Fig. 6, fold changes at each time point from qPCR were compared with the RNA-seq expression profiles, and all trends of qPCR results were significantly correlated well with the RNAseq expression profiles, suggesting that digital presentation of short reads in RNA-seq accurately reflects the transcriptome profiles. 


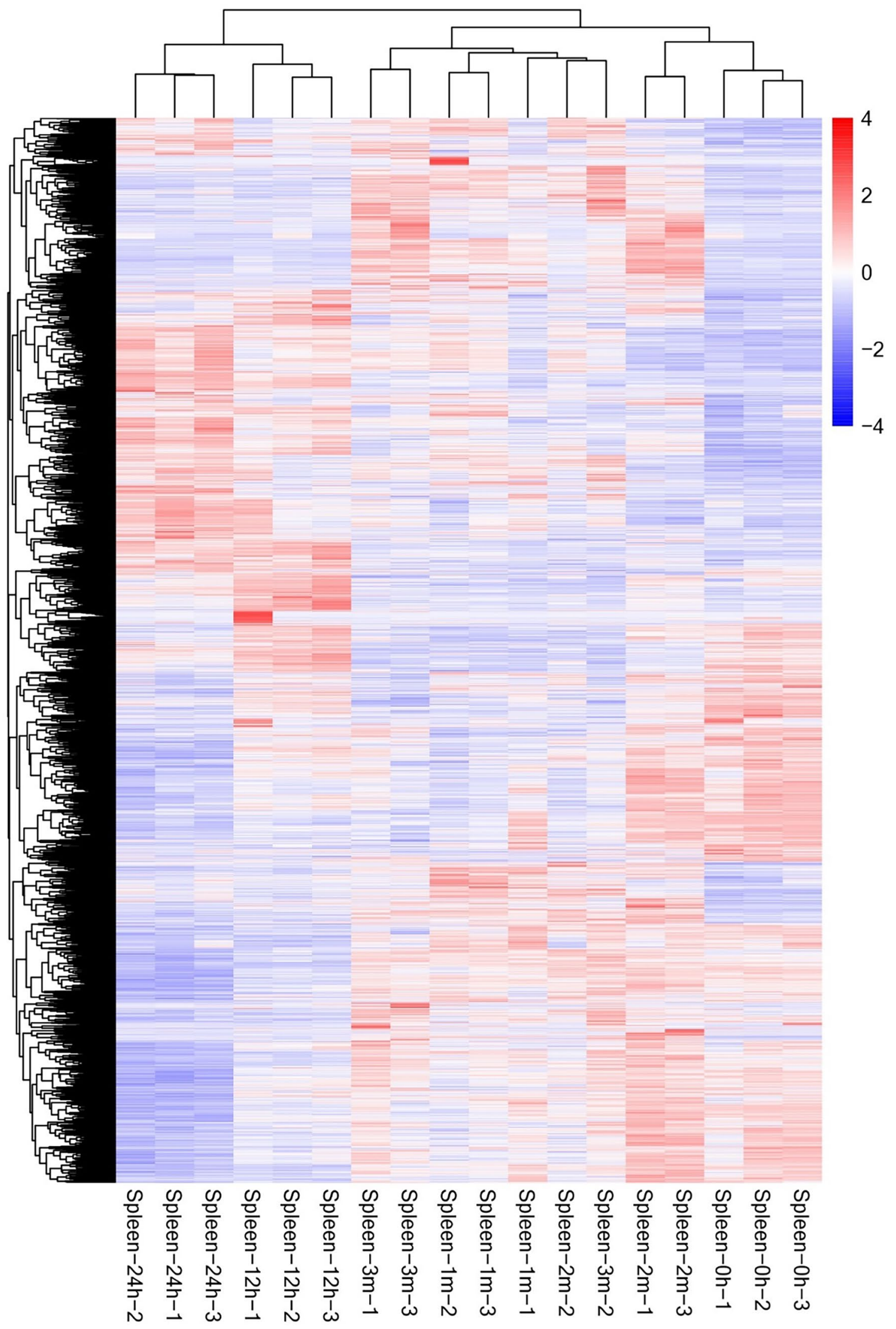


4Fig. 2 Heatmap display of hierarchical clustering of all DEGs in Atlantic salmon at different time points post-ASM vaccination. The DEGs are displayed in rows while samples are displayed in columns

\section{Discussion}

Atlantic salmon is one of the most economically important cold-water fish in aquaculture in marine and freshwater ecosystems (Andrew et al. 2021; Wang et al. 2019), which is seriously harmed by A. salmonicida. A. salmonicida is one of the most important bacterial fish pathogens that threaten Atlantic salmon, causing huge losses to the global salmon farming industry (Dallaire-Dufresne et al. 2014; Janda and Abbott 2010). A. salmonicida have the capability to infect non-phagocytic cells (Garduño et al. 2000; Valderrama et al. 2017) and phagocytic cells (Soto-Dávila et al. 2019). Once the fish is infected with the bacteria, the disease causes rapid septicemia resulting in the formation of necrotic lesions in the skin and hemorrhages in the internal organs, such infections are often fatal within as early as 2 or 3 days (Burr et al. 2005). Previous studies have revealed that $A$. salmonicida can greatly damage the immune organs of fish, after infection with A. salmonicida, symptoms such as exophthalmos, skin bleeding, ulcers, and necrosis in muscles and different internal organs (mainly spleen and kidneys) will occur (Burr et al. 2005). A. salmonicida subsp. masoucida (ASM) strains, recently isolated from several countries in Southeast Asia, were clustered in cluster VII among newly reported 14 clusters based on partial nucleotide sequences of the vapA gene (Gulla et al. 2016). Several ASM strains were reported to lead to huge economic damages to the local salmonid aquaculture in China (Du et al. 2015; Yan et al. 2021).

Vaccines are an effective way to prevent fish from being infected by bacterial diseases, and effective protection from A. salmonicida appeared to require injection of the vaccines (Krantz et al. 1963; Midtlyng et al. 1996b; Durbin et al. 1999). To contribute the knowledge base at the molecular level, we performed transcriptome analysis to identify the DEGs related to the Atlantic salmon spleen after intraperitoneal injection of the ASM vaccine, and better reflect the immune response of the spleen to the vaccination. In this study, a total of 441.63 million clean reads were obtained, and 389.37 million reads were mapped onto the Atlantic salmon reference genome. In addition, 1125, 2126, 1098, 820 , and 1351 genes were significantly up-regulated, and $747,2626,818,254$, and 908 genes were significantly downregulated post-ASM vaccination at $12 \mathrm{~h}, 24 \mathrm{~h}, 1 \mathrm{month}$, 2 months, and 3 months, respectively. It is worthy to mention that it would be more reasonable to set the time-matched mock-injection controls at each time point, since all comparisons in this study was conducted between pre-injected fish and immune-stimulated fish. The results of RT-qPCR showed a significant correlation with RNA-Seq results, suggesting the reliability of RNA-Seq for gene expression analysis. Many of the identified DEGs and overrepresented signaling pathways were involved in inflammation and immune response.

The innate immune system detects the presence and the nature of infection, provides the first line of host defense, and controls the initiation and determination of the effector class of the adaptive immune response (Zhang and Dong 2005). A specific immune response, such as the production of antibodies against a particular pathogen, is known as adaptive immune response, because it occurs during the lifetime of an individual as an adaptation to infection with that pathogen (Zhang and Dong 2005). Many signal transduction pathways participate in both innate and adaptive immune responses. From a combination of GO enrichment analysis and literature reviews, we can divide representative DEGs of Atlantic salmon into several major pathways such as cytokine-cytokine receptor interaction, HTLV-I infection, MAPK signaling pathway, PI3K-Akt signaling pathway, and TNF signaling pathway. Putative pathways involved in immune responses in Atlantic salmon spleen are illustrated as a diagram (Figs. 4 and 5). The putative functional roles and interaction of these signaling pathways are discussed below.

\section{Cytokine-Cytokine Receptor Interaction}

Cytokines are soluble extracellular proteins or glycoproteins that are crucial intercellular regulators and mobilizers of cells engaged in innate as well as adaptive inflammatory host defenses, cell growth, differentiation, cell death, angiogenesis, and development and repair processes aimed at the restoration of homeostasis. In this study, most of these DEGs enriched in this pathway were related to tumor necrosis factor receptors, interleukins, and chemokines. In detail, the TNF superfamilies are examples of signal transducers whose integrated actions impinge principally on the development, homeostasis, and adaptative responses of the immune system (Bodmer et al. 2002). In our work, the significant up-regulations of TNFRSF5, TNFRSF10b, and TNFRSF11b, and down-regulations of TNFRSF10a and TNFRSF16 were observed at almost all time points (Table 4). TNFRSF5 is constitutively expressed in a wide range of fish tissues, with relative high expression levels in immune tissues including spleen and head kidney (Park et al. 2005; Cai et al. 2017). It was reported that infection with Vibrio harveyi and i.p. injection of polyI:C could elevate TNFRSF5 transcript levels in the spleen of humphead snapper (Lutjanus sanguineus) (Cai et al. 2017). Noteworthily, DNA vaccination with viral hemorrhagic septicemia virus (VHSV) G-protein has been shown to up-regulate TNFRSF5 expression in Japanese flounder (Ju et al. 2005), which was consistent with our results. In addition, we 


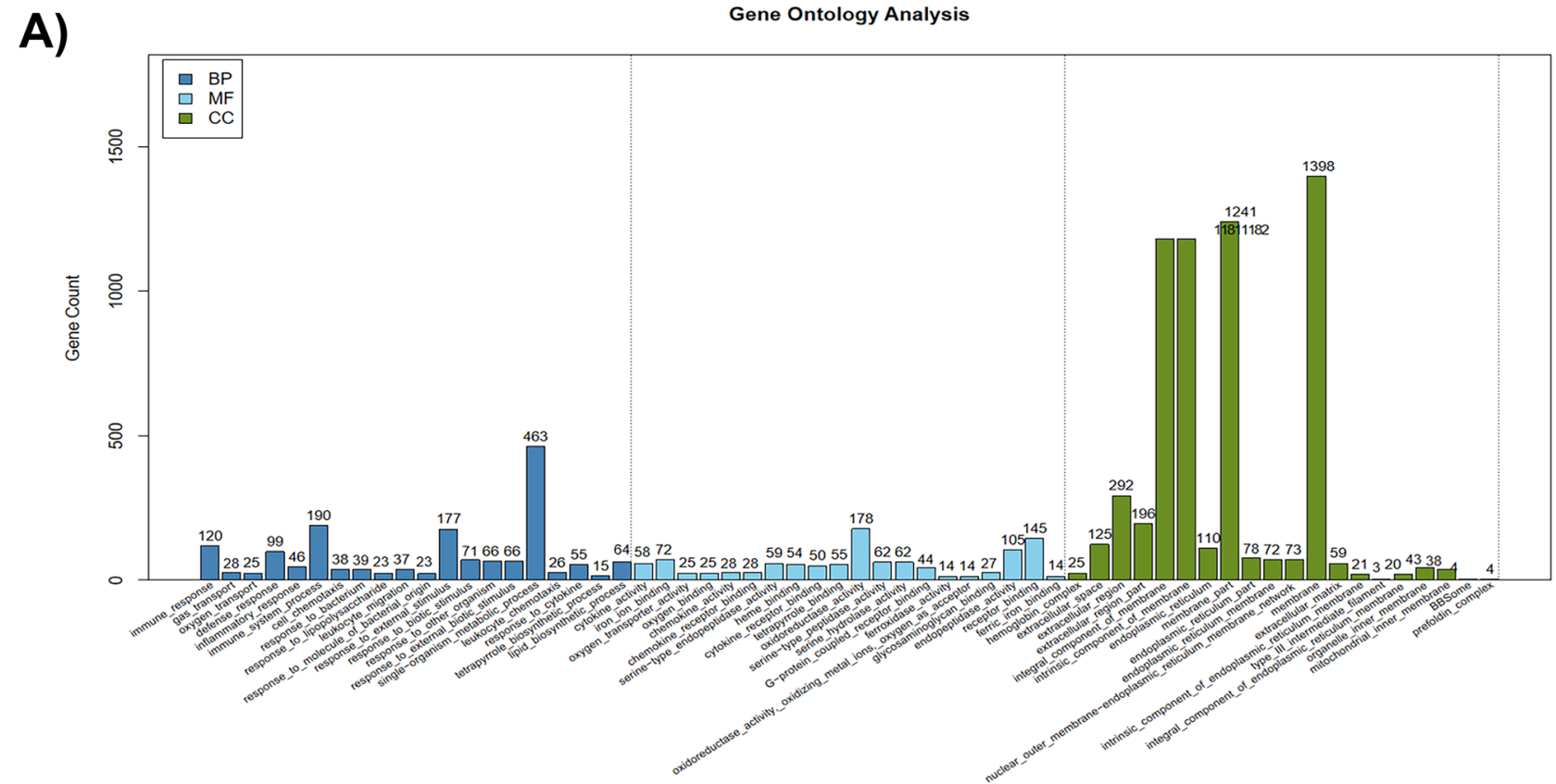

B)

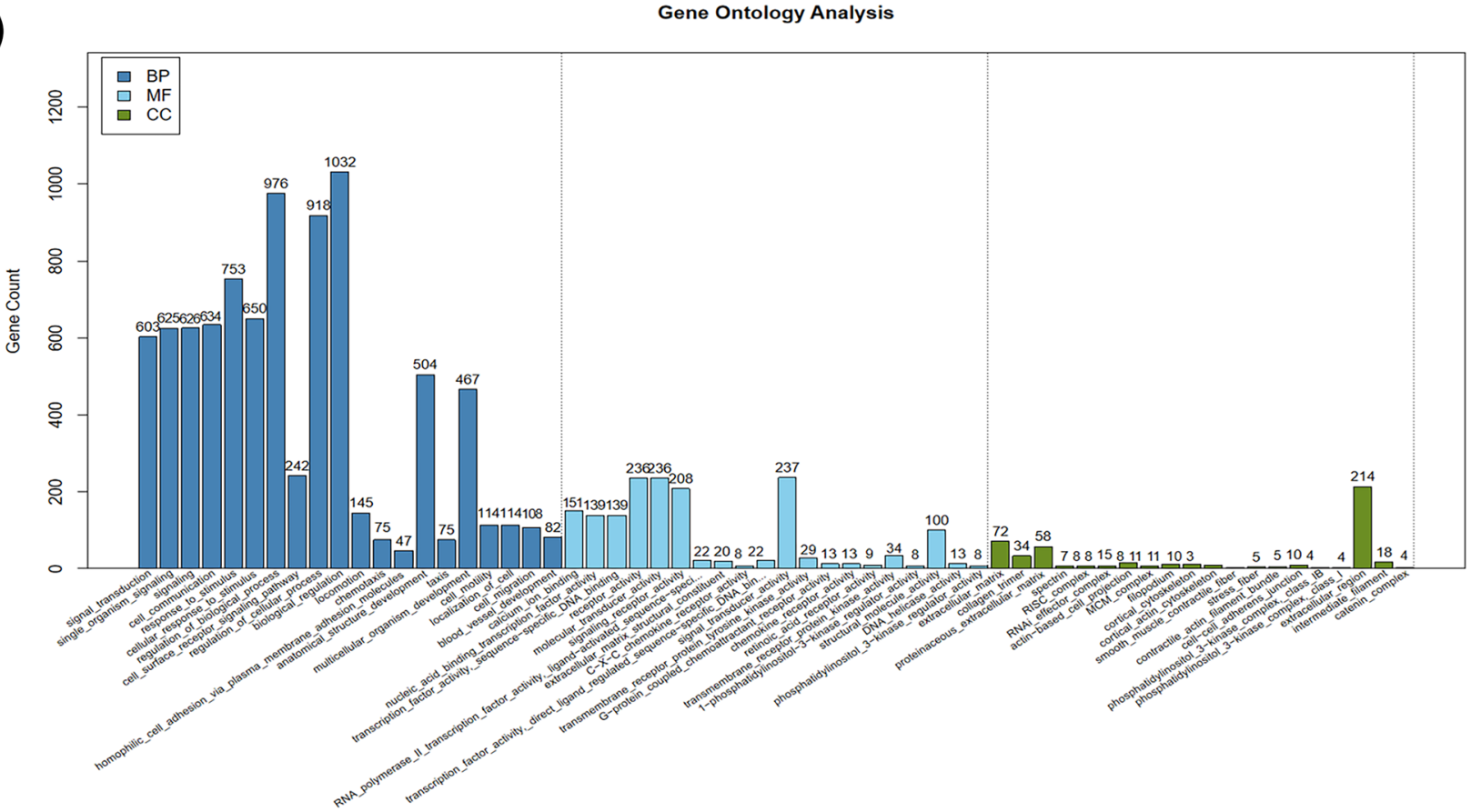

Fig. 3 Classification map of DEG secondary entries. The $x$-axis represents the second-level GO entry, and the $y$-axis represents the number of DEGs in the GO entry. A GO analysis of up-regulated DEGs. B GO analysis of down-regulated DEGs

found a number of chemokines and chemokine receptors differentially expressed after ASM vaccination at different time points. Chemokines promote leukocyte mobilization and regulate the immune responses and differentiation of the recruited cells (Alejo and Tafalla 2011; Esche et al. 2005). Besides their chemotactic function, several chemokines were reported to exert direct antimicrobial activity (Chan et al. 2008; Hasan et al. 2006; Nguyen and Vogel 2012). Increasing studies have been performing in aquaculture fish species, focused on immune function and their role in pathogenesis (Fu et al. 2017a, b, c; Wang et al. 2020; Zhao et al. 2020, 2021; Liao et al. 2018; Grimholt et al. 2015; Xu et al. 2020; Wang et al. 2020a, b; Li et al. 2021). 
A)

Statistics of Pathway Enrichment

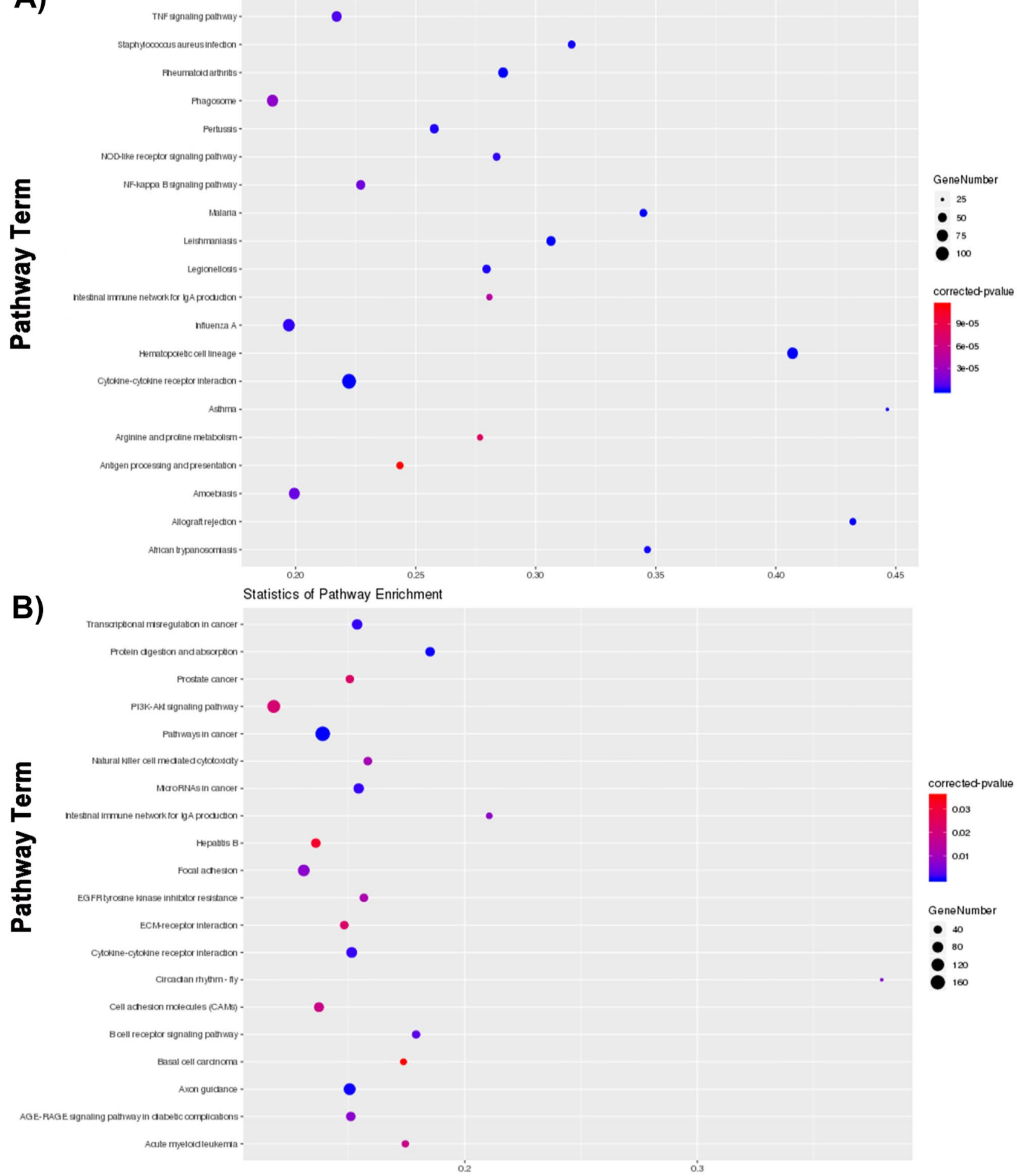

Fig. 4 Pathway analysis of DEGs between control group and vaccination-treated groups based on KEGG database (FDR-corrected $P$ value $<0.05)$. The vertical coordinates indicate the KEGG channel. The horizontal coordinates indicate the Rich factor. The larger the Rich factor, the greater the degree of enrichment. The larger the point, the greater the number of differential genes enriched in the pathway. A Pathway analysis of up-regulated DEGs. B Pathway analysis of down-regulated DEGs 
Table 4 Representative DEGs and their $\log _{2} \mathrm{FC}$ value in Atlantic salmon spleen post-ASM vaccination at different time points involved in key molecular pathways

\begin{tabular}{|c|c|c|c|c|c|}
\hline \multirow[t]{2}{*}{ Gene name } & \multicolumn{5}{|c|}{$\log _{2} \mathrm{FC}$} \\
\hline & $12 \mathrm{~h}$ & $24 \mathrm{~h}$ & 1 month & 2 months & 3 months \\
\hline \multicolumn{6}{|l|}{ Cytokine-cytokine receptor interaction } \\
\hline $\mathrm{C}-\mathrm{C}$ chemokine receptor type 7 & -1.11 & -1.15 & -0.9 & -0.93 & -1.05 \\
\hline $\mathrm{C}-\mathrm{C}$ chemokine receptor type 9 & -0.09 & -1.04 & -1.39 & -1.41 & -2.33 \\
\hline $\mathrm{C}-\mathrm{C}$ motif chemokine 4 & 4.5 & 4.67 & 2.84 & 3.05 & 4.03 \\
\hline CCL4-like chemokine & -0.59 & -1.17 & -1.1 & -1.33 & -1.41 \\
\hline $\mathrm{C}-\mathrm{X}-\mathrm{C}$ chemokine receptor type 3 & -1.28 & -0.34 & -1.6 & -1.13 & -2.57 \\
\hline C-X-C motif chemokine 11 & 2.17 & 1.47 & 1.85 & 1.51 & 1.23 \\
\hline Interleukin-17 receptor $\mathrm{A}$ & 0.16 & -0.76 & -1.44 & -1.17 & -1.57 \\
\hline Tumor necrosis factor receptor superfamily member $10 \mathrm{~A}$ & -0.64 & -1.61 & -1.4 & -1.17 & -1.27 \\
\hline Tumor necrosis factor receptor superfamily member $10 \mathrm{~B}$ & 1.02 & 1.63 & 1.43 & 0.44 & 1.36 \\
\hline Tumor necrosis factor receptor superfamily member 11B & 7.65 & 7.95 & 5.8 & 5.81 & 6.51 \\
\hline Tumor necrosis factor receptor superfamily member 16 & -1.13 & -2.45 & -1.77 & -0.92 & -1.12 \\
\hline Tumor necrosis factor receptor superfamily member 5 & 0.92 & 1.39 & 1.12 & 0.73 & 1.03 \\
\hline \multicolumn{6}{|l|}{ HTLV-1 infection } \\
\hline BOLA class I histocompatibility antigen, alpha chain BL3-7 & 1.26 & 1.67 & 1.87 & 1.81 & 2.03 \\
\hline Calcitonin gene-related peptide type 1 receptor & 2.3 & 2.24 & 0.88 & 1.56 & 0.52 \\
\hline cAMP-responsive element modulator & 5.57 & 4.8 & 2.05 & 2.03 & 1.96 \\
\hline Major histocompatibility complex class I-related gene protein & 1.35 & 2.08 & 3.11 & 2.67 & 2.4 \\
\hline Platelet-derived growth factor receptor alpha-like & 1.35 & 1.57 & 0.57 & 2.14 & 1.65 \\
\hline Proto-oncogene c-Fos & 2.91 & 1.02 & 2.14 & 3.2 & 1.28 \\
\hline \multicolumn{6}{|l|}{ MAPK signaling pathway } \\
\hline Calcium voltage-gated channel auxiliary subunit alpha2delta 4 & 1.94 & 1.73 & 1.46 & 1.32 & 1.58 \\
\hline Interleukin-18 binding protein & -2.22 & -2.56 & -2.21 & -0.89 & -2.97 \\
\hline Interleukin-1 beta & 6.53 & 3.9 & 3.3 & 3.06 & 1.85 \\
\hline Mitogen-activated protein kinase MLT & 2.29 & 2.18 & 1.43 & 1.55 & 0.94 \\
\hline Tumor necrosis factor alpha-1 precursor & 3.73 & -0.82 & 4.42 & 5.18 & 4.32 \\
\hline Tumor necrosis factor alpha-2 precursor & 7.66 & 4.33 & 7.35 & 8.23 & 6.71 \\
\hline \multicolumn{6}{|l|}{ PI3K-Akt signaling pathway } \\
\hline Collagen alpha-1(II) chain & 8.14 & - & - & 4.36 & - \\
\hline $\mathrm{H}-2$ class II histocompatibility antigen, A-K alpha chain & 1.55 & 1.53 & 1.41 & 1.5 & 0.67 \\
\hline Phosphatidylinositol 3-kinase regulatory subunit gamma & 1.17 & 1.4 & 1.62 & 2.25 & 1.43 \\
\hline Protein kinase N3 & 2.05 & 2.16 & 1.5 & 1.03 & 1.84 \\
\hline Thrombospondin-4-B & 2.87 & 2.82 & 4.52 & 5.05 & 4.41 \\
\hline \multicolumn{6}{|l|}{ TNF signaling pathway } \\
\hline $\mathrm{C}-\mathrm{X}-\mathrm{C}$ motif chemokine 10 & 1 & 0.13 & 2 & 1.88 & 1.74 \\
\hline FAS-associated death domain protein & 1.44 & 2.21 & 1.22 & 0.45 & 0.87 \\
\hline Matrix metalloproteinase-14 & 2.11 & 1.63 & 1.2 & 1.74 & 1.21 \\
\hline Prostaglandin G/H synthase 2 & 6.92 & 5.41 & 4.62 & 5.17 & 4.37 \\
\hline Proto-oncogene c-Fos & 2.91 & 1.02 & 2.14 & 3.2 & 1.28 \\
\hline Transcription factor jun-B & 4.82 & 3.83 & 3.1 & 2.58 & 2.62 \\
\hline Tumor necrosis factor receptor superfamily member 21 & 6.55 & 6.97 & 7.51 & 7.94 & 7.76 \\
\hline
\end{tabular}

\section{HTLV-1 Infection}

Human T-lymphotropic virus type 1 (HTLV-1) is one of the most important members of the retrovirus family, and it infects peripheral-blood mononuclear cells (PBMC), particularly CD4 $+\mathrm{T}$ cells, leading to various complications due to changes in cytokines production and cell-signaling pathways (Futsch et al. 2018; Keikha et al. 2020). In the HTLV-1 infection pathway, MHC class I family, as a target for anti-tumor and allogeneic immunity, code for key 


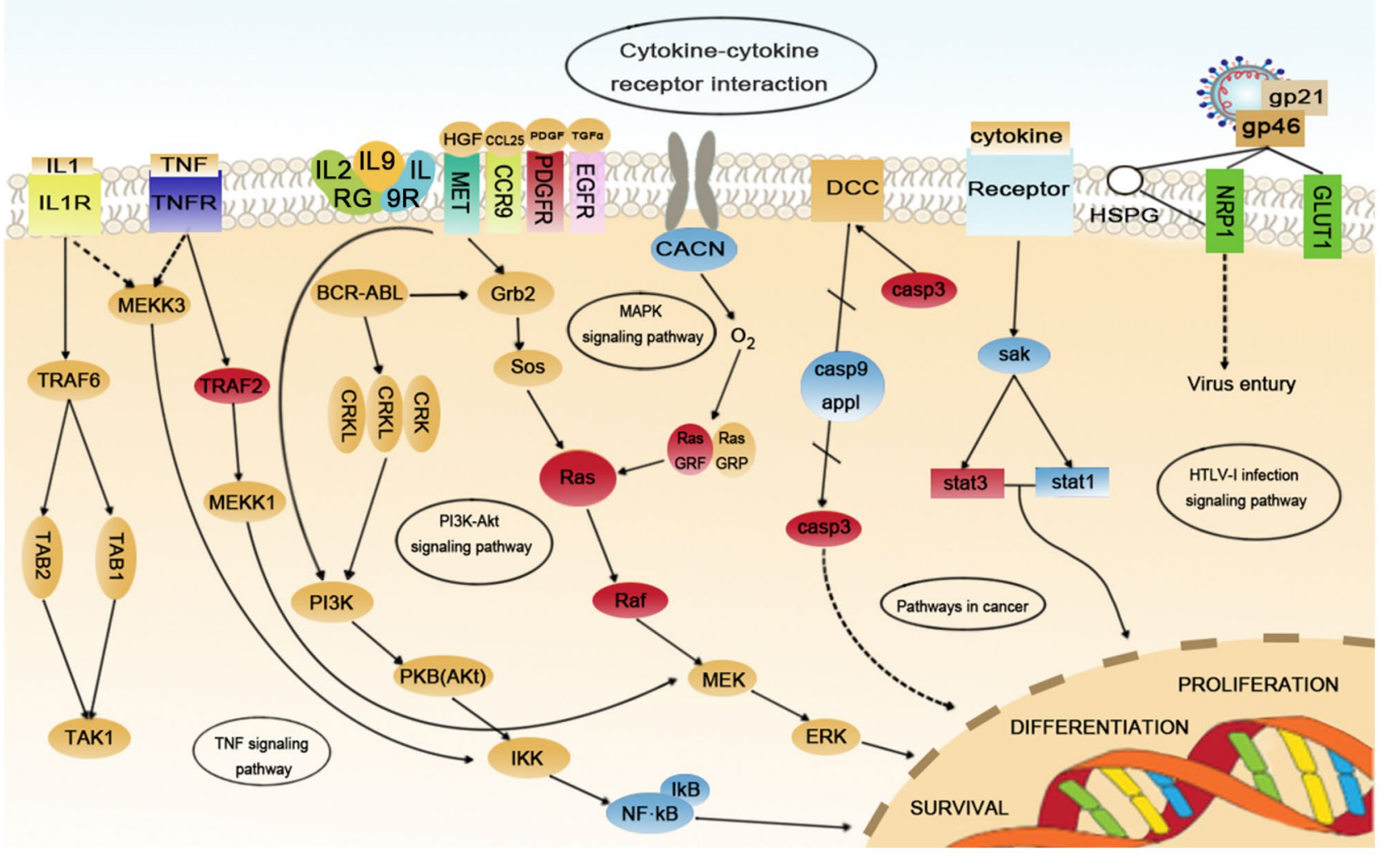

Fig. 5 Representative pathway analysis of DEGs between control group and vaccination-treated groups based on KEGG database (FDR-corrected $P$ value $<0.05$ )

proteins of the adaptive immune system, which present antigens from intra-cellular (MHC class I) and extra-cellular (MHC class II) pathogens (Minias et al. 2021; Ong et al. 2021). It plays a critical role in immunity by presenting peptides on the cell surface for $\mathrm{T}$ cell recognition (Mohan et al. 2021). In this study, MHC class I gene was significantly up-regulated with $\log _{2} \mathrm{FC}$ of 1.35, 2.08, 3.11, 2.67, and 2.4 at $12 \mathrm{~h}, 24 \mathrm{~h}, 1$ month, 2 months, and 3 months, respectively. In addition, platelet-derived growth factors (PDGFs) are among the best-characterized pro-fibrotic cytokines in systemic sclerosis, and it plays a key role in the pathogenesis of systemic sclerosis (Dragun et al. 2009). It has become apparent that members of the CREB family play important roles in the nuclear responses to a variety of external signals (Cesare et al. 1999). CREB and CREM play roles in many physiological systems, including memory and longterm potentiation, circadian rhythms, pituitary function, and spermatogenesis (Cesare et al. 1999). Through the sequencing results, it can be observed that the differential expression multiples of the CLEM gene in the HTLV pathway were the highest expression level at $12 \mathrm{~h}$ and $24 \mathrm{~h}$ post-vaccination, which indicates that this gene has a positive response to the vaccine. In this study, many immune-regulated genes in the HTLV-1 infection were identified as DEGs between vaccination-treated and control groups, suggesting a contribution of HTLV-1 infection to immune responses.

\section{MAPK Signaling Pathway}

The evolutionarily conserved mitogen-activated protein kinase (MAPK) cascades coordinately regulate a wide range of cellular processes, including cell proliferation, differentiation, metabolism, motility, survival, and apoptosis, and are therefore important for numerous physiological processes including innate and adaptive immune responses (Dickinson and Keyse 2006; Wagner and Nebreda 2009; Zhang and Dong 2005; Boon and Zhang 2016). Three major groups of MAPKs, namely the extracellular signal-regulated protein kinases (ERKs), the p38 MAP kinases, and the c-Jun $\mathrm{NH}_{2}$-terminal kinases (JNKs), have been identified in mammalian cells (Schaeffer and Weber 1999; Han and Ulevitch 1999; Davis 2000, Chang and Karin 2001). MAPK signaling responds to a broad range of extracellular signals from cytokines, growth factors, and environmental stresses (Krens et al. 2006; Tiedje et al. 2014). Meanwhile, MAPK signaling is subject to distinct spatiotemporal regulation by crosstalk and feedback mechanisms and can also cooperate with other pathways to control gene transcription (Menon 

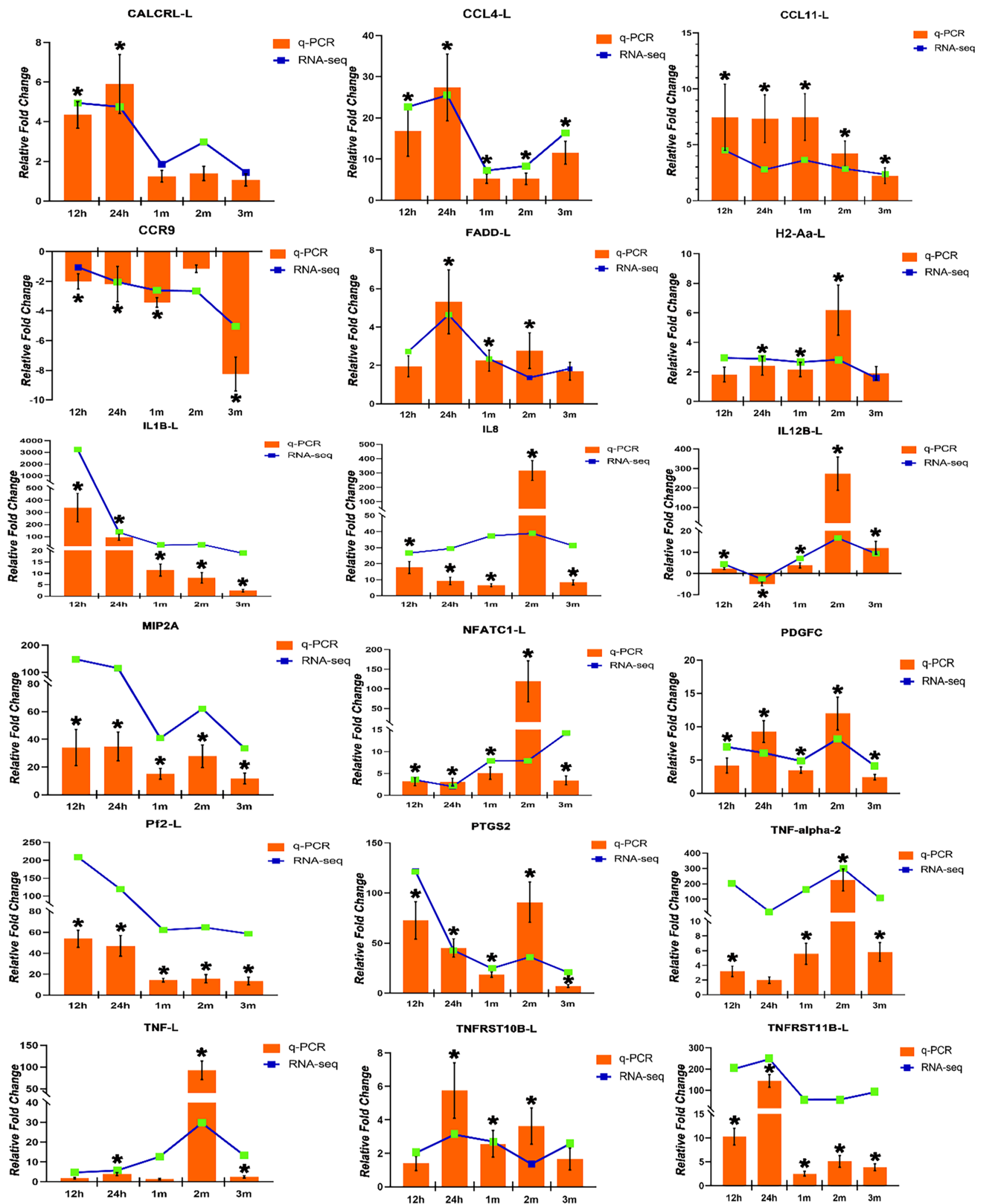

Fig. 6 Validation of RNA-seq results using qPCR. The $x$-axis represents the time points, and the $y$-axis represents the relative fold change. The results of qPCR were presented as mean \pm SE of fold change, and $*$ indicates significance at the 0.05 level. The blue line indicated the variation trend of RNA-Seq, and the green square indicates significance at the 0.05 level 
and Gaestel 2016; Jordan et al. 2000). Therefore, the MAPK cascade acts as an important integrator of signal transduction, which is crucial for many physiological and pathological processes (Sun et al. 2015), such as cell proliferation, differentiation, apoptosis, cancer, and almost all aspects of immune responses (Kim and Choi 2015; Sun et al. 2015; Peti and Page 2013; Arthur and Ley 2013; Dong et al. 2002). Many DEGs related to immunity were found in the MAPK enrichment pathway, such as interleukin-1 beta (IL-1b), mitogen-activated protein kinase kinase kinase MLT-like (MAP3K20-L), tumor necrosis factor alpha-1 precursor (TNF- $\alpha-1)$, tumor necrosis factor alpha- 2 precursor (TNF- $\alpha-2)$, calcium voltage-gated channel auxiliary subunit alpha2delta 4 , and interleukin-18 binding protein. In detail, interleukin is a key proinflammatory cytokines that enables organisms to respond to infection and induces a cascade of reactions leading to inflammation (Dinarello 2002). MAP3K family is associated with aging, inflammation, oxidative stress, and related diseases, which plays an important role in animal innate immune response (Cao et al. 2019; Wang et al. 2020a, b). The cytokine TNF- $\alpha$ is a powerful proinflammatory cytokine released by several immune cells during infection or tissue damage and is involved in a diverse range of inflammatory, infectious, and malignant conditions (Roca et al. 2008). All of them indicate that the Atlantic salmon spleen might be an important organ in response to the vaccine. In addition, as a critical activator of the MAPK signaling pathway, map3k-1 was induced in responses to vaccine with a $\log _{2} \mathrm{FC}$ of $0.94-2.29$ in our study.

\section{PI3K-Akt Signaling Pathway}

The PI3K/Akt pathway is one of the major signaling pathways that have been identified as important players in regulating cell proliferation, growth, survival, and angiogenesis (Zhang et al. 2021). Activated PI3K/AKT pathway contributes to cancer cell proliferation, survival, angiogenesis and inhibition of apoptosis, which are important factors of tumorigenesis (Chen et al. 2017). Apart from regulation of tumors, current evidence suggests PI3K/AKT can also modulate inflammation, apoptosis and immune cells proliferation, differentiation through regulating the activity of downstream effector molecules, such as NF- $\mathrm{KB}$, Bad, caspase-9, and m-TOR (Vivanco and Sawyers 2002; Way et al. 2016; Park et al. 2014). Additionally, numerous studies have indicated that the PI3K/AKT signaling pathway is an important intracellular signaling pathway that plays a role in a variety of cellular physiological processes, including cell proliferation, cell apoptosis, and inflammatory response ( $\mathrm{Li}$ et al. 2013; Jiang et al. 2019; Wang et al. 2020a, b). Chang et al. reported that 7-ketocholesterol contributed to thrombosis via the induction of endothelial damage, apoptosis, and inflammatory responses, which were associated with the activation of PI3K/AKT signaling (Chang et al. 2016).

In this study, thrombospondin-4-B-like (thbs4b-1), phosphatidylinositol 3-kinase regulatory subunit gamma (PIK3R3), protein kinase N3 (PKN3), collagen alpha-1(II) chain-like (Col2a1-1), H-2 class II histocompatibility antigen (H-2), A-K alpha chain-like genes related to this pathway were enriched. In detail, thrombospondin-4 (THBS4) is a member of the extracellular calcium-binding protein family. It is a secreted pentameric globular protein that forms part of the extracellular matrix, and functions in calcium binding, cell attachment, cell migration, cellular proliferation, cytoskeletal organization, neurite growth, binding of other extracellular matrix components, and cell to cell interactions (Stenina et al. 2003; Adams and Lawler 2004; Arber and Caroni 1995; Carlson et al. 2008; Si et al. 2003; van Doorn et al. 2005). The PIK3R3 regulatory subunit is crucial in cell proliferation, cell differentiation, tumor angiogenesis, and tumor growth (Wang et al. 2013, 2014, 2015). Protein kinase $\mathrm{N}(\mathrm{PKN})$ is a serine/threonine protein kinase with a catalytic domain homologous to protein kinase $\mathrm{C}$ and a unique regulatory region containing antiparallel coiled-coil (ACC) domains (Maesaki et al. 1999). PKN is composed of three isoforms (PKN1, PKN2, and PKN3) derived from different genes in mammals (Mukai et al. 2016). Previous reports have shown that ablation of the PKN3 gene suppressed migration of embryonic fibroblast cells induced by various growth factors (Mukai et al. 2016). So far, there have been accumulated reports about the potential function of PKN isoforms using cultured cell experiments such as involvement in the regulation of cytoskeletal reorganization (Vincent and Settleman 1997; Mukai et al. 1997), cell adhesion (Calautti et al. 2002, Wallace et al. 2011), cell-cycle regulation (Isagawa et al. 2005; Schmidt et al. 2007), and tumorigenesis (Metzger et al. 2003, Leenders et al. 2004). COL2A1 encodes for type II collagen, the most important and abundant extracellular matrix protein in epiphysis cartilage (Zhou et al. 2021). It is closely related to the development and maturation of chondrocytes, synthesis and catabolism of extracellular matrix, and cartilage ossification (Barat-Houari et al. 2016). Interestingly, the differential expression of COL2A1-1 is particularly up-regulated at $12 \mathrm{~h}$ after the injection of the vaccine, while there is almost no differential expression at $24 \mathrm{~h}$ and 1 month and 3 months after the injection. Its function in the spleen needs to be further studied.

\section{TNF Signaling Pathway}

TNF is a member of a superfamily of cytokines that consists of more than 20 structurally related transmembrane and soluble proteins, which play a crucial role in various biological events by recruiting several intracellular 
adaptors, thus activating multiple signal transduction pathways (Wajant et al. 2003). The proteins of the TNF receptor superfamily are a group of cell-surface receptors critically involved in the maintenance of homeostasis of the immune system (Tong et al. 2002). The members of the TNF receptor superfamily are intimately involved in the regulation of the proliferation and death of immune cells and are of particular interest in relation to their role in immuno-biology and the pathogenesis of autoimmune disease (Chan et al. 2000). Functionally, the members of the TNF receptor superfamily can deliver signals leading to apoptosis or proliferation/survival (Tong et al. 2002). In the present study, many DEGs related to tumor necrosis factor are enriched in this pathway, such as prostaglandin G/H synthase 2 (PTGS2), tumor necrosis factor receptor superfamily member 21-like (TNFRSF21-1), and C-X-C motif chemokine 10 (CXCL10). PTGS2 promotes inflammation and suppresses T-cell-mediated adaptive immunity (Cao et al. 2016). CXCL10 may play a role in chronic inflammatory diseases, including coronary artery disease and related manifestations of atherosclerosis (Heller et al. 2006).

Supplementary Information The online version contains supplementary material available at https://doi.org/10.1007/s10126-021-10089-6.

Funding This research was funded by the Joint Funds of the National Natural Science Foundation of China and Shandong Province, grant number U1706205; Keypoint Research and Invention Program in Shandong Province, grant number 2019GHY112025; the advanced Talents Foundation of QAU grant, grant number 665-1118015; Young Experts of Taishan Scholars, grant number tsqn201909130; Breeding Plan of Shandong Provincial Qingchuang Research Team (2019) supported by the "First class fishery discipline" program in Shandong Province, China; Shandong Technical System of Fish Industry (SDAIT-12-03); and a special talent program "One Thing One Decision (Yishi Yiyi)" Program in Shandong Province, China.

\section{Declarations}

Conflict of Interest The authors declare no competing interests.

\section{References}

Adams JC, Lawler J (2004) The thrombospondins. Int J Biochem Cell Biol 36:961-968

Alejo A, Tafalla C (2011) Chemokines in teleost fish species. Dev Comp Immunol 35:1215-1222

Ali A, Rexroad C, Thorgaard GH, Yao J, Salem M (2014) Characterization of the rainbow trout spleen transcriptome and identification of immune-related genes. Front Gen 5:348

Anders S, Pyl PT, Huber W (2015) HTSeq-a Python framework to work with high-throughput sequencing data. Bioinformatics 31:166-169

Andrew S, Primmer C, Debes P, Erkinaro J, Verta J (2021) The Atlantic salmon whole blood transcriptome and how it relates to major locus maturation genotypes and other tissues. Mar Genomics 56:100809
Andrew SC, Primmer CR, Debes PV, Erkinaro J, Verta JP (2020) The Atlantic salmon whole blood transcriptome and how it relates to major locus maturation genotypes and other tissues. Marine Genom 100809

Arber S, Caroni P (1995) Thrombospondin-4, an extracellular matrix protein expressed in the developing and adult nervous system promotes neurite outgrowth. J Cell Biol 131:1083-1094

Arthur J, Ley SC (2013) Mitogen-activated protein kinases in innate immunity. Nat Rev Immunol 13:679-692

Barat-Houari M, Sarrabay G, Gatinois V, Fabre A, Dumont B, Genevieve D, Touitou I (2016) Mutation update for COL2A1 gene variants associated with type II collagenopathies. Hum Mutat 37:7-15

Bjørgen H, Koppang E (2021) Anatomy of teleost fish immune structures and organs. Immunogenetics 73:53-63

Bodmer JL, Schneider P, Tschopp J (2002) The molecular architecture of the TNF superfamily. Trends Biochem Sci 27:19-26

Bolger AM, Lohse M, Usadel B (2014) Trimmomatic: a flexible trimmer for Illumina sequence data. Bioinformatics

Boon LH, Zhang Y (2016) Regulatory roles of MAPK phosphatases in cancer. Immune Network 16:85-98

Botwright NA, Mohamed AR, Slinger J, Lima PC, Wynne JW (2021) Host-parasite interaction of Atlantic salmon (Salmo salar) and the ectoparasite Neoparamoeba perurans in amoebic gill disease. Front Immunol 12:672700

Boyle EI, Weng S, Gollub J, Jin H, Botstein D, Cherry JM, Sherlock G (2004) GO::TermFinder-open source software for accessing Gene Ontology information and finding significantly enriched Gene Ontology terms associated with a list of genes. Bioinformatics 20:3710-3715

Burr S, Pugovkin D, Wahli T, Segner H, Frey J (2005) Attenuated virulence of an Aeromonas salmonicida subsp. salmonicida type III secretion mutant in a rainbow trout model. Microbiology (reading, England) 151:2111-2118

Cai J, Fan Y, Xia H, Lu Y, Jian J, Wu Z (2017) Identification and characterization of CD40 from humphead snapper (Lutjanus sanguineus). Fish Shellfish Immunol 70:665-672

Calautti E, Grossi M, Mammucari C, Aoyama Y, Pirro M, Ono Y, Li J, Dotto $\mathrm{G}$ (2002) Fyn tyrosine kinase is a downstream mediator of Rho/PRK2 function in keratinocyte cell-cell adhesion. J Cell Biol 156:137-148

Cao Y, Jin N, Fan M, Lv C, Song X, Jin P, Ma F (2019) Phylogenetically conserved TAK1 participates in Branchiostoma belcheri innate immune response to LPS stimulus. Fish Shellfish Immunol 94:264-270

Cao Y, Nishihara R, Qian ZR, Song M, Mima K, Inamura K, Nowak JA, Drew DA, Lochhead P, Nosho K (2016) Regular aspirin use associates with lower risk of colorectal cancers with low numbers of tumor-infiltrating lymphocytes. Gastroenterology 879-892.e4

Carlson CB, Lawler J, Mosher DF (2008) Structures of thrombospondins. Cell Mol Life Sci 65:672-686

Cesare DD, Fimia GM, Sassone-Corsi P (1999) Signaling routes to CREM and CREB: Plasticity in transcriptional activation. Trends Biochem Sci 24:281-285

Chan DI, Hunter HN, Tack BF, Vogel HJ (2008) Human macrophage inflammatory protein $3 \alpha$ : protein and peptide nuclear magnetic resonance solution structures, dimerization, dynamics, and antiinfective properties. Antimicrob Agents Chemother 52:883-894

Chan KF, Siegel MR, Lenardo JM (2000) Signaling by the TNF receptor superfamily and T cell homeostasis. Immunity 13:419-422

Chang L, Karin M (2001) Mammalian MAP kinase signalling cascades. Nature 410, 37-40

Chang MC, Chen YJ, Liou EJ, Tseng WY, Chan CP, Lin HJ, Liao WC, Chang YC, Jeng PY, Jeng JH (2016) 7-Ketocholesterol induces ATM/ATR, Chk1/Chk2, PI3K/Akt signalings, cytotoxicity and IL-8 production in endothelial cells. Oncotarget 7:74473-74483

Chen Q, Duan X, Fan H, Xu M, Tang Q, Zhang L, Shou Z, Liu X, Zuo D, Yang J, Deng S, Dong Y, Wu H, Liu Y, Nan Z (2017) 
Oxymatrine protects against DSS-induced colitis via inhibiting the PI3K/AKT signaling pathway. Int Immunopharmacol 53:149-157

Dallaire-Dufresne S, Tanaka K, Trudel M, Lafaille A, Charette S (2014) Virulence, genomic features, and plasticity of Aeromonas salmonicida subsp. salmonicida, the causative agent of fish furunculosis. Vet Microbiol 169:1-7

Davis RJ (2000) Signal transduction by the JNK group of MAP kinases. Cell 103:239-252

Dickinson R, Keyse S (2006) Diverse physiological functions for dualspecificity MAP kinase phosphatases. J Cell Sci 119:4607-4615

Dinarello CA (2002) The IL-1 family and inflammatory diseases. Clin Exp Rheumatol 20:S1

Dong C, Davis RJ, Flavell RA (2002) MAP kinases in the immune response. Annu Rev Immunol 20:55-72

Dragun D, Distler J, Riemekasten G, Distler O (2009) Stimulatory autoantibodies to platelet-derived growth factor receptors in systemic sclerosis: what functional autoimmunity could learn from receptor biology. Arthritis Rheum 60:907-911

Du Y, Yi M, Xiao P, Meng L, Li X, Sun G, Liu Y (2015) The impact of Aeromonas salmonicida infection on innate immune parameters of Atlantic salmon (Salmo salar L). Fish Shellfish Immunol 44:307-315

Durbin M, Mcintosh D, Smith PD, Wardle R, Austin B (1999) Immunization against furunculosis in rainbow trout with iron-regulated outer membrane protein vaccines: relative efficacy of immersion, oral, and injection delivery. J Aquat Anim Health 11:68-75

Esche C, Stellato C, Beck LA (2005) Chemokines: key players in innate and adaptive immunity. J Investig Dermatol 125:615-628

FAO (2018) The State of World Fisheries and Aquaculture 2018 Meeting the sustainable development goals. Rome. Licence: CC BY-NC-SA 3.0 IGO

Flajnik M (2018) A cold-blooded view of adaptive immunity. Nat Rev Immunol 18:438-453

Fu Q, Yang Y, Li C, Zeng Q, Zhou T, Li N, Liu Y, Li Y, Wang X, Liu S, Li D, Liu Z (2017a) The chemokinome superfamily: II. The $64 \mathrm{CC}$ chemokines in channel catfish and their involvement in disease and hypoxia responses. Dev Comp Immunol 73:97-108

Fu Q, Yang Y, Li C, Zeng Q, Zhou T, Li N, Liu Y, Liu S, Liu Z (2017b) The CC and CXC chemokine receptors in channel catfish (Ictalurus punctatus) and their involvement in disease and hypoxia responses. Dev Comp Immunol 77:241-251

Fu Q, Zeng Q, Li Y, Yang Y, Li C, Liu S, Zhou T, Li N, Yao J, Jiang C, Li D, Liu Z (2017c) The chemokinome superfamily in channel catfish: I. CXC subfamily and their involvement in disease defense and hypoxia responses. Fish Shellfish Immunol 60:380-390

Futsch N, Prates G, Mahieux R, Casseb J, Dutartre H (2018) Cytokine networks dysregulation during HTLV-1 infection and associated diseases. Viruses 10

Garduño R, Moore A, Olivier G, Lizama A, Garduño E, Kay W (2000) Host cell invasion and intracellular residence by Aeromonas salmonicida: role of the S-layer. Can J Microbiol 46:660-668

Garrity GM (2001) Bergey's manual of systematic bacteriology / George M. Garrity, editor-in-chief: Bergey's manual of systematic bacteriology / George M. Garrity, editor-in-chief

Gjessing M, Krasnov A, Timmerhaus G, Brun S, Afanasyev S, Dale O, Dahle M (2020) The Atlantic salmon gill transcriptome response in a natural outbreak of salmon gill pox virus infection reveals new biomarkers of gill pathology and suppression of mucosal defense. Front Immunol 11:2154

Grimholt U, Hauge H, Hauge AG, Leong J, Koop BF (2015) Chemokine receptors in Atlantic salmon. Dev Comp Immunol 49:79-95

Grove S, Johansen R, Reitan LJ, Press CM, Dannevig BH (2006) Quantitative investigation of antigen and immune response in nervous and lymphoid tissues of Atlantic halibut
(Hippoglossus hippoglossus) challenged with nodavirus. Fish Shellfish Immunol 21:525-539

Gudmundsdottir BK, Jonsdottir H, Steinthorsdottir V, Magnadottir B, Gudmundsdottir S (2010) Survival and humoral antibody response of Atlantic salmon, Salmo salar L., vaccinated against Aeromonas salmonicida ssp. achromogenes. J Fish Dis 20:351-360

Gulla S, Lund V, Kristoffersen AB, Sorum H, Colquhoun DJ (2016) vapA (A-layer) typing differentiates Aeromonas salmonicida subspecies and identifies a number of previously undescribed subtypes. J Fish Dis 39:329-342

Han J, Ulevitch RJ (1999) Emerging targets for anti-inflammatory therapy. Nat Cell Biol 1:E39

Hasan L, Mazzucchelli L, Liebi M, Lis M, Hunger RE, Tester A, Overall CM, Wolf M (2006) Function of liver activation-regulated chemokine/CC chemokine ligand 20 is differently affected by cathepsin B and cathepsin D processing. J Immunol 176:6512-6522

Heller E, Liu E, Tager A, Yuan Q, Lin A, Ahluwalia N, Jones K, Koehn S, Lok V, Aikawa E, Moore K, Luster A, Gerszten R (2006) Chemokine CXCL10 promotes atherogenesis by modulating the local balance of effector and regulatory $\mathrm{T}$ cells. Circulation 113:2301-2312.

Hwang SD, Bae JS, Jo DH, Kim KI, Cho MY, Jee BY, Park MA, Park CI (2015) Gene expression and functional characterization of serum amyloid $\mathrm{P}$ component 2 in rock bream, Oplegnathus fasciatus. Fish Shellfish Immunol 47:521-527

Ingerslev HC, Pettersen EF, Jakobsen RA, Petersen CB, Wergeland HI (2006) Expression profiling and validation of reference gene candidates in immune relevant tissues and cells from Atlantic salmon (Salmo salar L.). Mol Immunol 43:1194-1201

Isagawa T, Takahashi M, Kato T, Mukai H, Ono Y (2005) Involvement of protein kinase PKN1 in G2/M delay caused by arsenite. Mol Carcinog 43:1

Janda JM, Abbott SL (2010) The genus Aeromonas: taxonomy, pathogenicity, and infection. Clin Microbiol Rev 23:35-73

Jiang Z, Chen Z, Chen Y, Jiao J, Wang Z (2019) RETRACTED ARTICLE: Involvement of pro-inflammatory cytokines in diabetic neuropathic pain via central PI3K/Akt/mTOR signal pathway. Arch Physiol Biochem 1-9

Jordan JD, Landau EM, Iyengar R (2000) Signaling networks: the origins of cellular multitasking. Cell 103:193-200

Ju YB, Ohira T, Hirono I, Aoki T (2005) Use of a cDNA microarray to study immunity against viral hemorrhagic septicemia (VHS) in Japanese flounder (Paralichthys olivaceus) following DNA vaccination. Fish Shellfish Immunol 18:135-147

Kanehisa M (2013) Molecular Network Analysis of Diseases and Drugs in KEGG. Methods Mol Biol 939:263-275

Keikha M, Ghazvini K, Eslami M, Yousefi B, Casseb J, Yousefi M, Karbalaei M (2020) Molecular targeting of PD-1 signaling pathway as a novel therapeutic approach in HTLV-1 infection. Microb Pathog 144:104198

Kim A, Yoon D, Lim Y, Roh HJ, Kim DH (2020) Co-expression network analysis of spleen transcriptome in rock bream (Oplegnathus fasciatus) naturally infected with rock bream iridovirus (RBIV). Int J Mole Sci 21:1707

Kim EK, Choi EJ (2015) Compromised MAPK signaling in human diseases: an update. Arch Toxicol 89:867-882

Krantz GE, Ecliff RD, J.M. \& Heist, C. (1963) Development of antibodies against Aeromonas salmonicida in trout. J Immunol 91:757-760

Krens S, Spaink H, Snaar-Jagalska B (2006) Functions of the MAPK family in vertebrate-development. FEBS Lett 580:4984-4990

Leenders F, Möpert K, Schmiedeknecht A, Santel A, Czauderna F, Aleku M, Penschuck S, Dames S, Sternberger M, Röhl T, Wellmann A, Arnold W, Giese K, Kaufmann J, Klippel A (2004) PKN3 is required for malignant prostate cell growth downstream of activated PI 3-kinase. EMBO J 23:3303-3313 
Li G, Zhao Y, Liu Z, Gao C, Yan F, Liu B, Feng J (2015) De novo assembly and characterization of the spleen transcriptome of common carp (Cyprinus carpio) using Illumina paired-end sequencing. Fish Shellfish Immunol 44:420-429

Li Y, Jiang Y, Wan Y, Zhang L, Tang W, Ma J, Wu S, Cheng W (2013) Medroxyprogestogen enhances apoptosis of SKOV-3 cells via inhibition of the PI3K/Akt signaling pathway. J Biomed Res 27:43-50

Li Y, Zhang P, Gao C, Cao M, Yang N, Li X, Li C, Fu Q (2021) $\mathrm{CXC}$ chemokines and their receptors in black rockfish (Sebastes schlegelii): Characterization, evolution analyses, and expression pattern after Aeromonas salmonicida infection. Int J Biol Macromol 186:109-124

Liao Z, Wan Q, Xiao X, Ji J, Su J (2018) A systematic investigation on the composition, evolution and expression characteristics of chemokine superfamily in grass carp Ctenopharyngodon idella. Dev Comp Immunol 82:72-82

Lien S, Koop BF, Sandve SR, Miller JR, Kent MP, Nome T, Hvidsten TR, Leong JS, Minkley DR, Zimin A, Grammes F, Grove H, Gjuvsland A, Walenz B, Hermansen RA, Von Schalburg K, Rondeau EB, Di Genova A, Samy JKA, Olav Vik J, Vigeland MD, Caler L, Grimholt U, Jentoft S, Inge Våge D, De Jong P, Moen T, Baranski M, Palti Y, Smith DR, Yorke JA, Nederbragt AJ, ToomingKlunderud A, Jakobsen KS, Jiang X, Fan D, Hu Y, Liberles DA, Vidal R, Iturra P, Jones SJM, Jonassen I, Maass A, Omholt SW, Davidson WS (2016) The Atlantic salmon genome provides insights into rediploidization. Nature 533:200-205

Livak KJ, Schmittgen TD (2001) Analysis of relative gene expression data using real-time quantitative PCR and the 2(-Delta Delta C(T)) Method. Methods 25:402-408

Maekawa S, Wang P, Chen S (2019) Comparative study of immune reaction against bacterial infection from transcriptome analysis. Front Immunol 10:153

Maesaki R, Ihara K, Shimizu T, Kuroda S, Kaibuchi K, Hakoshima $\mathrm{T}$ (1999) The structural basis of Rho effector recognition revealed by the crystal structure of human RhoA complexed with the effector domain of PKN/PRK1. Mol Cell 4(5):793-803

Magnadóttir B (2006) Innate immunity of fish (overview). Fish Shellfish Immunol 20:137-151

Martin SA, Blaney SC, Houlihan DF, Secombes CJ (2006) Transcriptome response following administration of a live bacterial vaccine in Atlantic salmon (Salmo salar). Mol Immunol 43:1900-1911

Menon MB, Gaestel M (2016) TPL2 meets p38MAPK: emergence of a novel positive feedback loop in inflammation. Biochem $\mathrm{J}$ 473:2995

Metzger E, Müller JM, Ferrari S, Buettner R, Schüle R (2003) A novel inducible transactivation domain in the androgen receptor: implications for PRK in prostate cancer. EMBO J 22(2):270-280

Midtlyng PJ, Reitan LJ, Lillehaug A, Ramstad A (1996a) Protection, immune responses and side effects in Atlantic salmon (Salmo salar $\mathrm{L}$.) vaccinated against furunculosis by different procedures. Fish Shellfish Immunol 6:599-613

Midtlyng PJ, Reitan LJ, Speilberg L (1996b) Experimental studies on the efficacy and side-effects of intraperitoneal vaccination of Atlantic salmon (Salmo salar L.) against furunculosis. Fish Shellfish Immunol 6:335-350

Milla S, Mathieu C, Wang N, Lambert S, Nadzialek S, Massart S, Henrotte E, Douxfils J, Mélard C, Mandiki S (2010) Spleen immune status is affected after acute handling stress but not regulated by cortisol in Eurasian perch, Perca fluviatilis. Fish Shellfish Immunol 28:931-941

Minias P, Włodarczyk R, Remisiewicz M, Cobzaru I, Janiszewski T (2021) Distinct evolutionary trajectories of MHC class I and class II genes in Old World finches and buntings. Heredity 126(6):974-990. https://doi.org/10.1038/s41437-021-00427-8
Mohan S, Datta K, Ziegman R, Smith C, Gowda H (2021) Protocol for purification and identification of MHC class I immunopeptidome from cancer cell lines. STAR Protocols 2:100385

Mukai H, Muramatsu A, Mashud R, Kubouchi K, Tsujimoto S, Hongu T, Kanaho Y, Tsubaki M, Nishida S, Shioi G (2016) PKN3 is the major regulator of angiogenesis and tumor metastasis in mice. Sci Rep 6:18979

Mukai H, Toshimori M, Shibata H, Takanaga H, Ono Y (1997) Interaction of PKN with $\alpha$-Actinin. J Biol Chem 272:4740-4746

Nguyen LT, Vogel HJ (2012) Structural perspectives on antimicrobial chemokines. Front Immunol 3:384

Ong C, Patchett A, Darby J, Chen J, Liu G, Lyons A, Woods G, Flies A (2021) NLRC5 regulates expression of MHC-I and provides a target for anti-tumor immunity in transmissible cancers. J Cancer Res Clin Oncol 147(7) 1973-1991. https://doi.org/10.1007/ s00432-021-03601-x

Papetti C, Harms L, Windisch HS, Frickenhaus S, Sandersfeld T, Jürgens J, Koschnick N, Knust R, Pörtner H, Lucassen M (2015) A first insight into the spleen transcriptome of the notothenioid fish Lepidonotothen nudifrons: Resource description and functional overview. Mar Genom

Park CI, Hirono I, Hwang JY, Aoki T (2005) Characterization and expression of a CD40 homolog gene in Japanese flounder Paralichthys olivaceus. Immunogenetics 57:682-689

Park S, Regmi SC, Park SY, Lee EK, Chang JH, Ku SK, Kim DH, Kim JA (2014) Protective effect of 7-O-succinyl macrolactin A against intestinal inflammation is mediated through PI3-kinase/ $\mathrm{Akt} / \mathrm{mTOR}$ and NF-kB signaling pathways. Eur J Pharmacol 735:184-192

Peti W, Page R (2013) Molecular basis of MAP kinase regulation. Protn Ence 22:1698-1710

Qi Z, Wu P, Zhang Q, Wei Y, Wang Z, Qiu M, Shao R, Li Y, Gao Q (2016) Transcriptome analysis of soiny mullet (Liza haematocheila) spleen in response to Streptococcus dysgalactiae. Fish Shellfish Immunol 49:194-204

Reith ME, Singh RK, Curtis B, Boyd JM, Bouevitch A, Kimball J, Munholland J, Murphy C, Sarty D, Williams J (2008) The genome of Aeromonas salmonicida subsp. salmonicida A449: insights into the evolution of a fish pathogen. BMC Genomics 9:427-427

Robinson M, Mccarthy D, Smyth G (2010) edgeR: a Bioconductor package for differential expression analysis of digital gene expression data. Bioinformatics (oxford, England) 26:139-140

Roca FJ, Mulero I, Lopez-Munoz A, Sepulcre MP, Renshaw SA, Meseguer J, Mulero V (2008) Evolution of the inflammatory response in vertebrates: fish TNF-alpha is a powerful activator of endothelial cells but hardly activates phagocytes. J Immunol 181:5071-5081

Schaeffer HJ, Weber MJ (1999) Mitogen-activated protein kinases: specific messages from ubiquitous messengers. Mol Cell Biol 19:2435-2444

Schmidt A, Durgan J, Magalhaes A, Hall A (2007) Rho GTPases regulate PRK2/PKN2 to control entry into mitosis and exit from cytokinesis. Embo J 26(6):1624-1636.

Si Z, Palkama A, Gebhardt B, Velasquez D, Galeano M, Beuerman R (2003) Distribution of thrombospondin-4 in the bovine eye. Curr Eye Res 27:165-173

Soto-Dávila M, Hossain A, Chakraborty S, Rise M, Santander J (2019) Aeromonas salmonicida subsp. Early Infection and Immune Response of Atlantic Cod (L.) Primary Macrophages. Front Immunol 10:1237

Stenina O, Desai S, Krukovets I, Kight K, Janigro D, Topol E, Plow E (2003) Thrombospondin-4 and its variants: expression and differential effects on endothelial cells. Circulation 108:1514-1519

Sun Y, Liu WZ, Tao L, Xu F, Zhou HF (2015) Signaling pathway of MAPK/ERK in cell proliferation, differentiation, migration, 
senescence and apoptosis. J Recept Signal Transduct Res 35:600-604

Tiedje C, Holtmann H, Gaestel M (2014) The role of mammalian MAPK signaling in regulation of cytokine mRNA stability and translation. J Interferon Cytokine Res 34:220-232

Tong Z, Mountz JD, Kimberly RP (2002) Immunobiology of tumor necrosis factor receptor superfamily. Immunol Res 26:323-336

Valderrama K, Saravia M, Santander J (2017) Phenotype of Aeromonas salmonicida sp. salmonicida cyclic adenosine 3',5'-monophosphate receptor protein (Crp) mutants and its virulence in rainbow trout (Oncorhynchus mykiss). J Fish Dis 40:1849-1856

Van Doorn R, Zoutman W, Dijkman R, De Menezes R, Commandeur S, Mulder A, Van Der Velden P, Vermeer M, Willemze R, Yan P, Huang T, Tensen C (2005) Epigenetic profiling of cutaneous T-cell lymphoma: promoter hypermethylation of multiple tumor suppressor genes including BCL7a, PTPRG, and p73. J Clin Oncol: Offi J Am Soc Clin Oncol 23:3886-3896

Villumsen KR, Dalsgaard I, Holten-Andersen L, Raida MK (2012) Potential role of specific antibodies as important vaccine induced protective mechanism against Aeromonas salmonicida in rainbow trout. PLoS One 7:e46733

Vincent S, Settleman J (1997) The PRK2 kinase is a potential effector target of both Rho and Rac GTPases and regulates actin cytoskeletal organization. Mol Cell Biol 17:2247

Vivanco I, Sawyers CL (2002) The phosphatidylinositol 3-Kinase AKT pathway in human cancer. Nat Rev Cancer 2:489-501

Wagner E, Nebreda A (2009) Signal integration by JNK and p38 MAPK pathways in cancer development. Nat Rev Cancer 9:537-549

Wajant H, Pfizenmaier K, Scheurich P (2003) Tumor necrosis factor signaling. Cell Death Differ 10:45-65

Wallace SW, Magalhaes A, Hall A (2011) The Rho target PRK2 regulates apical junction formation in human bronchial epithelial cells. Mol Cell Biol 31:81-91

Wang G, Deng Y, Cao X, Lai S, Tong Y, Luo X, Feng Y, Xia X, Gong J, Hu J (2014) Blocking p55PIK signaling inhibits proliferation and induces differentiation of leukemia cells. Cell Death Diff 19(11):1870-1879

Wang Y, Chi L, Liu Q, Xiao Y, Ma D, Xiao Z, Xu S, Li J (2019) Effects of stocking density on the growth and immunity of Atlantic salmon salmo salar reared in recirculating aquaculture system (RAS). J Oceanol Limnol 37:352-362

Wang G, Cao X, Lai S, Luo X, Feng Y, Wu J, Ning Q, Xia X, Wang J, Gong J (2015) Altered p53 regulation of miR-148b and p55PIK contributes to tumor progression in colorectal cancer. Oncogene 34:912-921

Wang G, Cao X, Lai S, Luo X, Feng Y, Xia X, Yen PM, Gong J, $\mathrm{Hu}$ J (2013) PI3K stimulates DNA synthesis and cell-cycle progression via its p55PIK regulatory subunit interaction with PCNA. Mol Cancer Ther 12:2100-2109

Wang J, Deng B, Liu Q, Huang Y, Chen W, Li J, Zhou Z, Zhang L, Liang B, He J, Chen Z, Yan C, Yang Z, Xian S, Wang L (2020) Pyroptosis and ferroptosis induced by mixed lineage kinase 3 (MLK3) signaling in cardiomyocytes are essential for myocardial fibrosis in response to pressure overload. Cell Death Dis 11:574

Wang J, Meng Z, Wang G, Fu Q, Zhang M (2020) A CCL25 chemokine functions as a chemoattractant and an immunomodulator in black rockfish, Sebastes schlegelii. Fish Shellfish Immunol 100:161-170

Wang L, Feng Z, Wang X, Wang X (2010) DEGseq: an R package for identifying differentially expressed genes from RNA-seq data. Bioinformatics 26:136-138

Wang Z, Gerstein M, Snyder M (2009) RNA-Seq: a revolutionary tool for transcriptomics. Nat Rev Genet 10:57-63

Way EE, Trevejo-Nunez G, Kane LP, Steiner BH, Puri KD, Kolls JK, Chen K (2016) Dose-Dependent Suppression of Cytokine production from T cells by a Novel Phosphoinositide 3-Kinase Delta Inhibitor. Rep 6:30384

Xu H, Xing J, Tang X, Sheng X, Zhan W (2020) The effects of CCL3, CCL4, CCL19 and CCL21 as molecular adjuvants on the immune response to VAA DNA vaccine in flounder (Paralichthys olivaceus). Dev Comp Immunol 103:103492

Yan Y, Liu Y, Mo Z, Li J, Li G (2021) Development of Aeromonas salmonicida subsp. masoucida vaccine in turbot and evaluation of protection efficacy under field conditions. Aquaculture 737035

Zhang Y, Wang H, Li H, Nan L, Xu W, Lin Y, Chu K (2021) Gualou Guizhi granule protects against OGD/R-induced injury by inhibiting cell pyroptosis via the PI3K/Akt signaling pathway. Evid Based Complement Alternat Med 2021:6613572

Zhang YL, Dong C (2005) MAP kinases in immune responses. Cell Mol Immunol 2:20-27

Zhao J, Bai H, Ke Q, Li B, Xu P (2020) Genomic selection for parasitic ciliate Cryptocaryon irritans resistance in large yellow croaker. Aquaculture 531:735786

Zhao S, Li Y, Cao M, Yang N, Hu J, Xue T, Li C, Fu Q (2021) The CC and $\mathrm{CXC}$ chemokine receptors in turbot (Scophthalmus maximus L.) and their response to Aeromonas salmonicida infection. Dev Comp Immunol 123:104155

Zhou T, Yang X, Chen Z, Zhou Y, Cao X, Zhao C, Zhao J (2021) A novel COL2A1 mutation causing spondyloepiphyseal dysplasia congenita in a Chinese family. J Clin Lab Anal 35:e23728

Publisher's Note Springer Nature remains neutral with regard to jurisdictional claims in published maps and institutional affiliations. 